Check for updates

Cite this: RSC Adv., 2017, 7, 40158

\title{
Phytogenic magnetic nanoparticles for wastewater treatment: a review $\dagger$
}

\begin{abstract}
Imran Ali, ${ }^{a}$ Changsheng Peng, ${ }^{* a}$ Iffat Naz, (D) *b Zahid M. Khan, ${ }^{c}$ Muhammad Sultan, ${ }^{c}$ Tariqul Islam ${ }^{a}$ and Irfan Ahmed Abbasi ${ }^{a}$

Presently, there is an emerging research trend in the fabrication of Phytogenic Magnetic Nanoparticles (PMNPs) and their applications in the water/wastewater treatment (WWT), due to their dynamic morphology, desired size, super paramagnetic behavior and high saturation magnetization value. Green fabrication of PMNPs is clean, non-toxic, eco-friendly, fast and cost-effective as compared to other physico-chemical technologies, which make it a promising technology. However, certain aspects such as the optimization of the fabrication protocol in order to produce desired quality of PMNPs, regeneration and reusability, are the main hindrances in the transfer of this technology from the laboratory scale to the commercial applications. Therefore, the present study highlights the performance of PMNPs for the removal of aqueous pollutants from wastewater. In addition, the research developments of PMNPs regarding fabrication mechanism, regeneration and reusability for WWT are discussed. The study also provides a model of PMNPs based on zero effluent discharge and consequently, the WWT process is proposed. Finally, future perspectives and challenges are discussed to make PMNPs based green nanotechnology technically more feasible and economically sustainable.
\end{abstract}

Received 27th April 2017

Accepted 9th June 2017

DOI: $10.1039 / \mathrm{c} 7 \mathrm{ra04738j}$

rsc.li/rsc-advances use in water and wastewater treatment (WWT). ${ }^{1-3}$ The production and application of the PMNPs are clean, non-toxic, costeffective, fast and environmentally friendly. ${ }^{4}$ Conventional methods such as physical and chemical treatments are
There is a growing research interest in the fabrication of the noble Phytogenic Magnetic Nanoparticles (PMNPs) and their
'Department of Agricultural Engineering, Bahauddin Zakariya University, Bosan Road, Multan 60800, Pakistan

$\dagger$ Electronic supplementary information (ESI) available: Fig. S1 available. See DOI: $10.1039 / \mathrm{c} 7 \mathrm{ra04738j}$

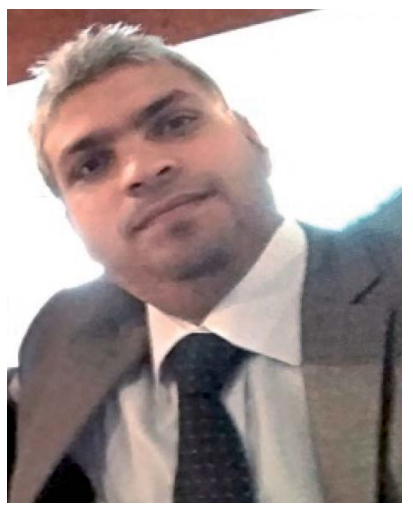

Imran Ali is currently pursuing Ph.D in Environmental Engineering from Ocean University of China (OUC), China. Previously, he earned his M.Sc. (Hons.) from Department of Agricultural Engineering, Bahauddin Zakariya University (BZU), Multan, Pakistan. In 2012, during his master study at BZU, he designed a trickling filter wastewater treatment system using agricultural waste materials as filter. In 2016, he joined the College of Environmental Science and Engineering at OUC as Ph.D. Scholar. He is interested in the development of novel magnetic nanoparticles, such as magnetosomes (MS) by magnetotactic bacteria (MTB), biogenic and phytogenic nanoparticles via biomineralization and green nanotechnology for wastewater treatment.

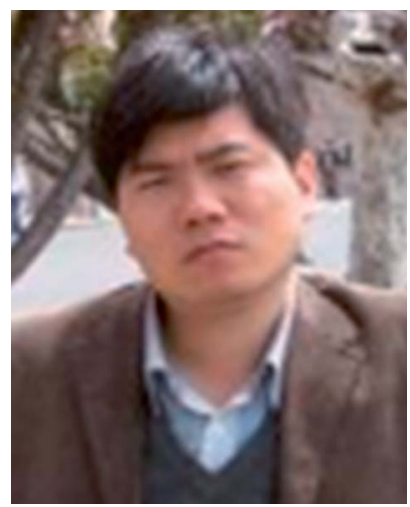

Dr Changsheng Peng is working as a full professor in the College of Environmental Science and Engineering, Ocean University, Qingdao, China since 2005. During his Ph.D, he designed an electrochemical wastewater treatment system and this technology got patents. Presently, Dr Peng has 15 registered international and national patents relating to wastewater treatment. He won postdoctoral research fellowship from the government of Mexico in 2003 and also worked as a visiting professor in Universidad Autonoma de san Luis Potosi, Mexico. Currently, he is interested in the development of cost effective novel nanoparticles via green nanotechnology for wastewater treatment. 
considered toxic, complicated and expensive due to the exploitation of hazardous and flammable chemicals that can cause environmental risks. ${ }^{1,5-7}$

Among all biogenic methods, green fabrication of the PMNPs can be performed at safe temperature and pressure. Moreover, plant metabolites (e.g. polyphenol, amino acids, polysaccharides) can be utilized as reducing and capping agents for the reduction of metal ions due to their reductive capacities. ${ }^{8,9}$ Employment of the PMNPs has been observed in biomedicine and environmental protection applications. ${ }^{\mathbf{1 0}}$ While in WWT processes, PMNPs have depicted superior performance in the removal of toxic dyes, pigments, refractory/ persistent pollutants and recovery of the heavy metals. Moreover, most researchers reported that PMNPs are better than

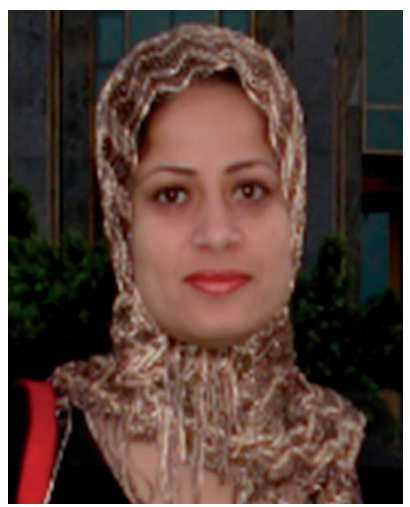

Iffat Naz earned PhD in Applied and Environmental Microbiology, from Quaid-i-Azam University, Islamabad, Pakistan, in 2014. During her PhD, she designed fixed biofilm reactors for wastewater treatment in collaboration with Department of Civil and Environmental Engineering, George Washington University, USA and Department of Civil and Environmental Engineering, University of Surrey, UK. Dr Nazjoined Department of Biology, Deanship of Educational Services, Qassim University, KSA as an Assistant Professor, in 2015. Currently she is involved with a research group of Environmental Engineering, Ocean University of China, for the fabrication of novel magnetic nanoparticles by bacteria and plants for wastewater treatment and environmental applications.

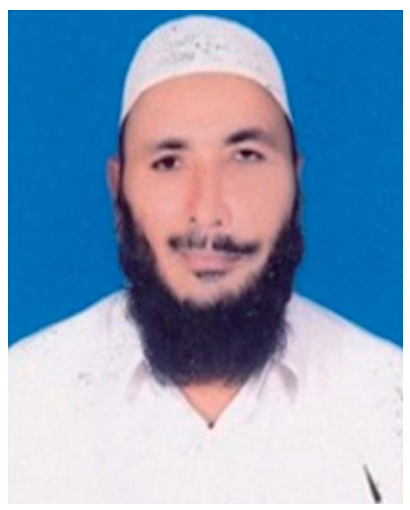

Professor Dr Zahid Mahmood Khan is currently working as chairman of the Department of Agricultural Engineering, Bahauddin Zakariya University, Multan, Pakistan. In 2005, he did Ph.D in Civil Engineering from University of British Columbia (UBC), Vancouver, Canada and achieved excellent research award from the Government of Canada for designing a novel biological wastewater treatment process for the removal of micro-organic pollutants. Later, in 2016, he designed a cost effective trickling filter wastewater treatment system and won technology innovation award from Higher Education Commission, Pakistan. Presently he is interested in the development of nanomaterials from agricultures by-products for wastewater treatment. conventional nanoparticles (NPs), particularly in terms of adsorptive removal and resources recovery. ${ }^{\mathbf{1 1 - 1 4}}$

PMNPs can be employed in the removal of aqueous pollutants and the recovery of metallic ions due to the presence of organic functional groups (e.g. polyphenols, amino acids, sugars, alkaloids, terpenoids, proteins, carbonyl, carboxyl, and polysaccharides), unique morphology, desired size, super paramagnetic behavior and high saturation magnetization valve from wastewater. ${ }^{15,16}$ Most often, PMNPs act like the ion-exchange resins and pollutants can be removed via electrostatic attractions due to the presence of specific organic functional groups from plant metabolites. In addition, desired standard and morphology of the PMNPs can be achieved by modifying the fabrication protocol and by manipulating the organic functional groups for specific pollutants

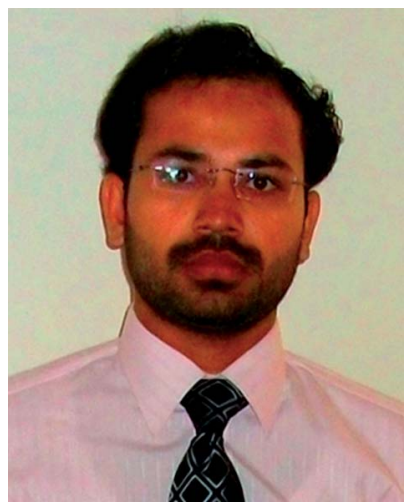

Dr Muhammad Sultan is an Assistant Professor in the Department of Agricultural Engineering, Bahauddin Zakariya University, Multan, Pakistan. He obtained Ph.D. in Energy and Environmental Engineering from Kyushu University, Japan in 2015. He worked as Research Support Staff for two years at WPI:I $I^{2}$ CNER, Kyushu University, which is a leading World Premier International Research Center of Japan. His main research interests include Adsorption Cooling, Evaporative Cooling, Maisotsenko-Cycle (M-Cycle), HVAC systems, and Wastewater Treatment, for Agricultural Applications. Currently he is involved in the development of low cost plant mediated nanoparticles for domestic wastewater treatment.

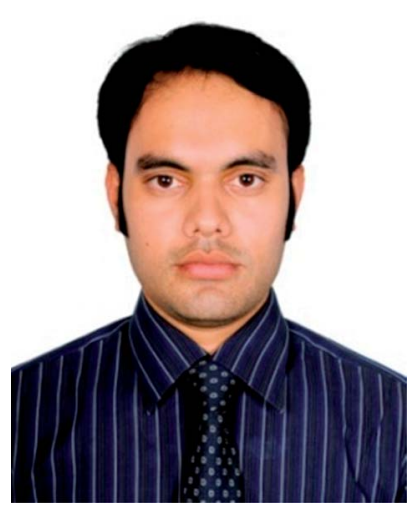

Tariqul Islam is working as an Assistant Professor at Department of Agricultural Construction and Environmental Engineering, Sylhet Agricultural University, Sylhet, Bangladesh since 2015. During his master study, his research interest was the removal of heavy metals from groundwater. In 2016, he joined college of Environmental Science and Engineering, Ocean University of China (OUC), China as PhD scholar. He is interested in the development of novel magnetic nanoparticles via biological routes for wastewater treatment. 
removal from wastewater. While, super paramagnetic behavior and high saturation magnetization value of PMNPs is also fascinating the WWT experts because they can be easily separated from final effluents and can be reused in consecutive treatment cycles, ${ }^{2}$ particularly in the recovering of heavy and precious metals for competing industrial demand..$^{\mathbf{8 , 1 5 , 1 7}}$

However, some aspects such as optimization of fabrication protocol for bulk production, controlled morphology and size, biocompatibility, employment of specific organic functional groups and fate of organic functional groups during targeted pollutants removal are hindered to transfer the PMNPs base technology from laboratory to commercial applications. Furthermore, loss of the PMNPs stability particularly due to the degradation of organic functional groups and iron leakage during pollutants removal can influence the WWT treatment performance, its reusability and resource recovery potential. ${ }^{13,18,19}$

Therefore, this review is an attempt to highlight performance of PMNPs in WWT, especially employment of the PMNPs in the removal of aqueous pollutants from wastewater. Further, detailed information are also considered regarding pollutants elimination mechanisms, regeneration and reusability of PMNPs and potential of resource recovery. Herein, inspired by the published reports, a model of the PMNPs based on zero effluent discharge WWT system is proposed particularly for developing and under developing economies. Moreover, most recent developments in the fabrication mechanisms of the PMNPs from various plants and their parts are taken into account and appreciated.

\section{Nanoparticles fabrication techniques and applications}

Nanotechnology is considered an emerging and cutting edge technology with wide range of applications in different fields of science. ${ }^{5}$ From past few decades, there is an increasing research interest in the formation of a novel nano material particularly for biomedical and environmental protection. ${ }^{6}$ The main goal of nanotechnology is to fabricate a nanoparticle or material of desire nanosize and shape by manipulating and controlling the properties of matter using physical, chemical and biological approaches. In addition, a specific scheme/method is developed to manufacture nanoparticles (NPs) of desired shape, size and composition, suitable for specific applications. ${ }^{7,20}$ However, particularly for environmental application, the fabricated NPs should have following characteristics including, (i) extremely small size, (ii) desire shape, (iii) high specific surface area, (iv) high surface area to volume ratio, (v) high catalytic ability, (vi) charge opposite to targeted pollutants, (vii) large number of active sites for pollutants adsorption, (viii) strong mechanical properties, (ix) nontoxic, (x) magnetic in nature for easily separating from final effluents, (xi) superparamagnetic in nature, and (xii) can be manufactured in bulk amount. ${ }^{21}$ Further, these features make NPs a suitable candidate for wide range of biotechnological applications e.g. catalysts, next generation biosensors, medical diagnostic systems, drug delivery, cancer therapy and pollutants removal. ${ }^{22}$

Fig. 1 depicts that there are two main ways to fabricate NPs such as top down and bottom up. ${ }^{23}$ In top down approach,

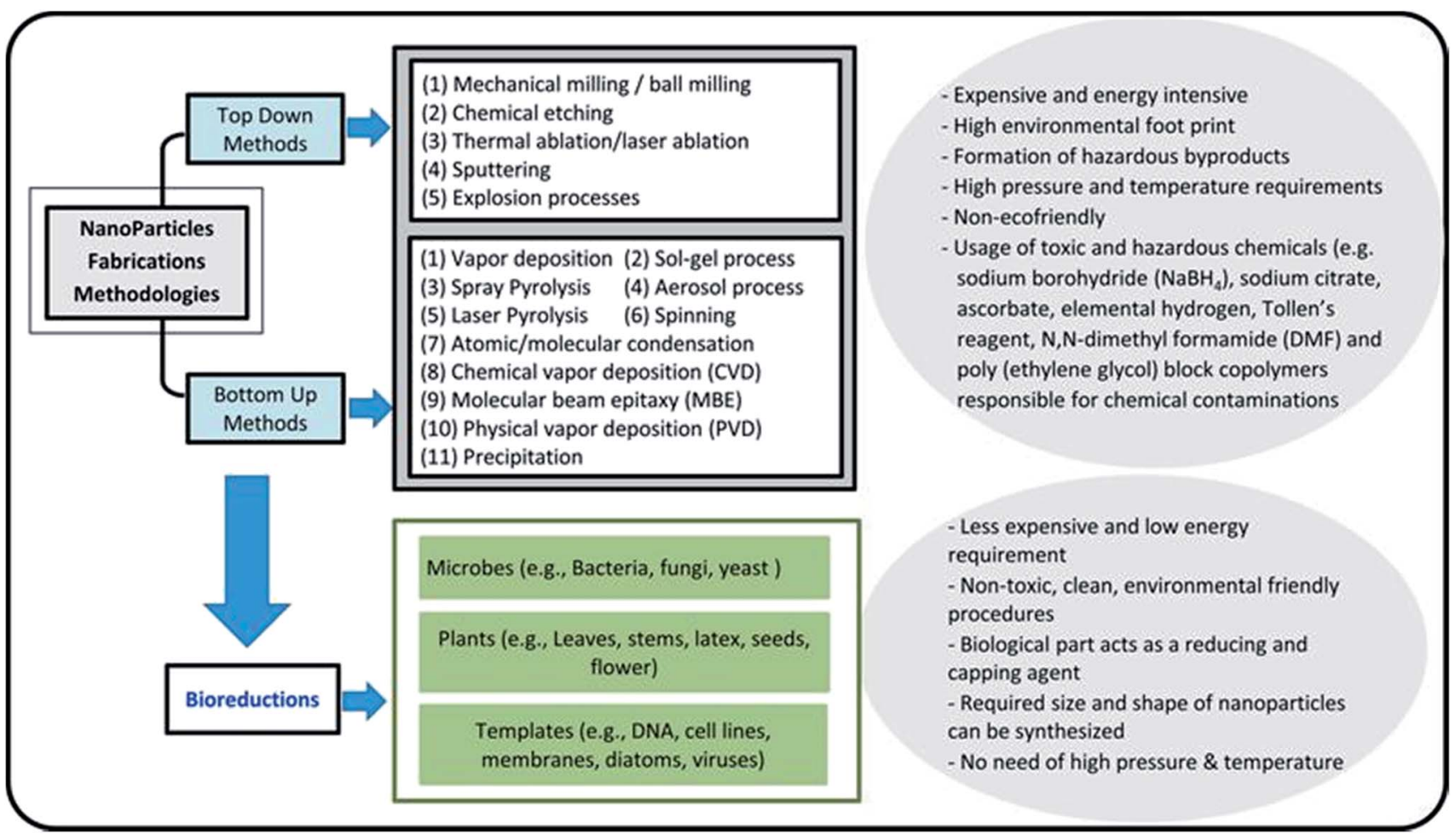

Fig. 1 Quick overview of the approaches and techniques to fabricate the nanoparticles (NPs). 


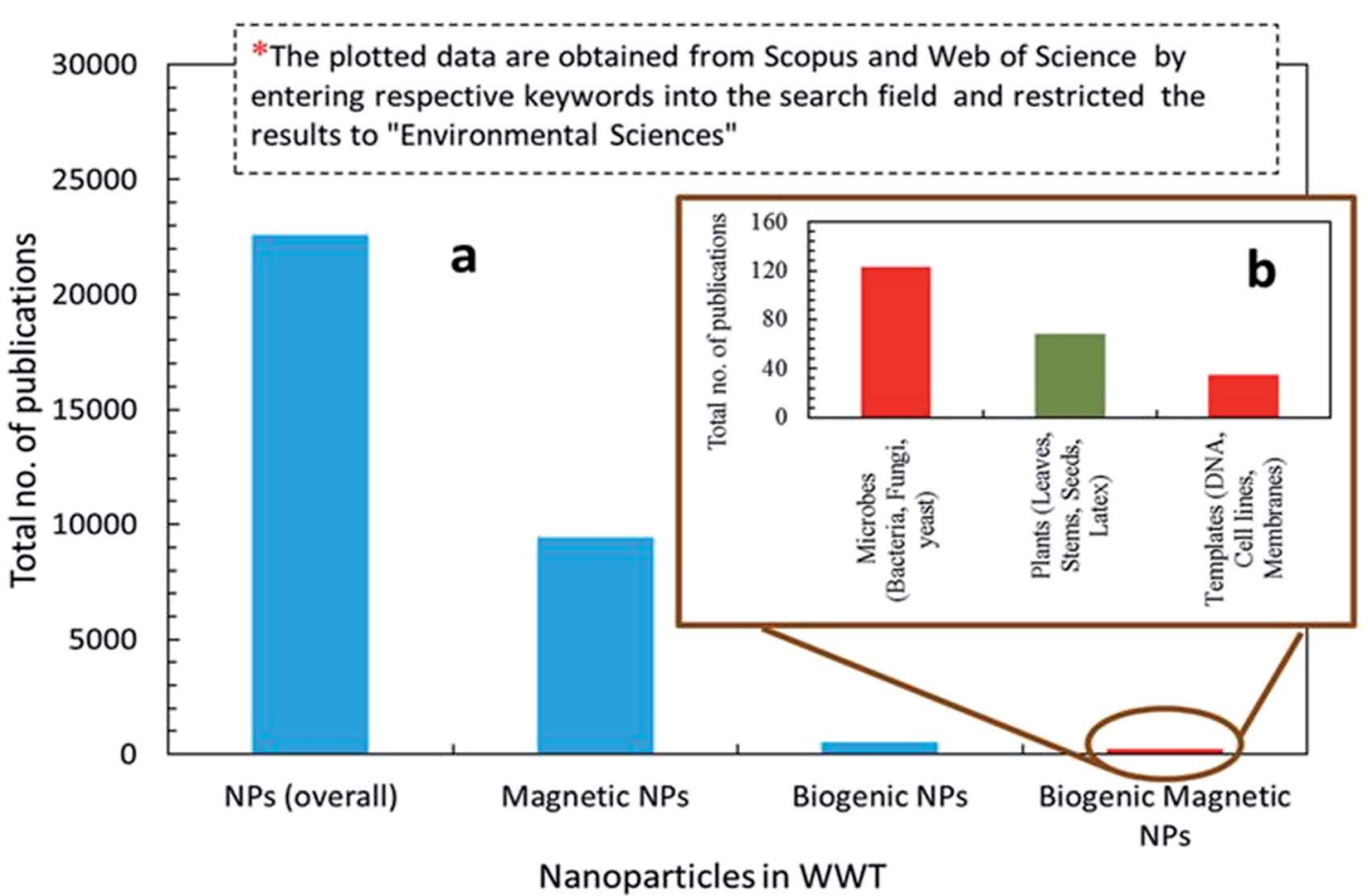

Fig. 2 Literature survey of the nanoparticles (NPs) applications in wastewater treatment (WWT): (a) overall; and (b) particularly biogenic magnetic nanoparticles (BMNPs) including phytogentic magnetic nanoparticles (PMNPs) in WWT. Plotted data is obtained from http:// apps.webofknowledge.com and https://www.scopus.com.

physical means are employed to fabricate NPs. ${ }^{9}$ On the other side, chemical and biological approaches are used in bottom up method. ${ }^{15}$ Generally, physical and chemical methods are employed to manufacture NPs with desire quality and quantity. ${ }^{24}$ However, these methods are hazardous and harmful to environment and human beings due to the use of toxic chemicals and the prerequisites of high temperature and pressure. Employment of NPs for WWT are superior to others technologies but have limitations such as separation from final effluents, and adverse ecotoxicological effects. These shortcomings are hindering its application in the WWT and deviated research studies towards the development of noble NPs, such as magnetic nanoparticles (MNPs), which can be easily recovered from the effluent. Fig. 2 shows the rapidly changing trend in the fabrication of NPs and their applications in the WWT. However, the manufacturing approaches of MNPs slowed down its applications due to the use of toxic and hazardous chemicals required as a reducing, capping and stabilizing agent for its production. ${ }^{7}$ Hence, there is a need to explore non-toxic, less energy consuming and environmental friendly methods to fabricate MNPs without using toxic and hazardous chemicals. In this regard, currently bio-reduction method using plants, microbes and templates is gaining great attention as an alternative method especially for synthesis PMNPs with desired qualities for WWT. ${ }^{4}$

\section{Bio-reduction approach for NPs fabrication}

Bio-reduction is basically a biological approach to fabricate NPs using microbes, plant species and templates. ${ }^{25-27}$ It is considered as green technology for producing NPs. The ability of biological entities such as microbes and plants to absorb and accumulate organic pollutants and inorganic metallic ions from surrounding environment has attracted scientists to employ them for the removal of pollutants and recovery of metals from industrial effluents. ${ }^{28}$ Moreover, both microbes and plants have potential to change oxidation state of metals under well-defined environmental condition. A wide variety of NPs can be fabricated using different biological entities such as bacteria, fungi, algal, viruses, yeast and plants. It is because that each entity possesses ability of biochemical processing where NPs formation occurs due to the oxidation-reduction of metallic ions via enzymes, sugars, proteins, polyphenol, aldehyde, carboxyl groups by the microbes and plant species (Fig. 1). Different kind of biogenic nanoparticles (BNPs) can be synthesized using different metallic ions using different biological entities (e.g. gold, silver, alloy, silica, titanium, palladium, selenium, antimony sulfide, etc.). ${ }^{29}$ These BNPs have been also employed for wide range of biomedical and environmental protections applications. It can be observed from the published literature that BNPs have been used for the removal of heavy metals, toxic dyes, halogenated compounds, pesticides, pharmaceutical and personal care products from industrial effluents (Fig. 2). ${ }^{8,15,48,61,76}$ These wide ranges of applications and safe synthesis procedure make BNPs superior than others NPs which are being synthesized via chemical and physical ways. Microbes, particularly microorganisms, are producing NPs via biological processes or biomineralization in the environment e.g. iron and Si-based nano-minerals crystal. $^{30}$ 


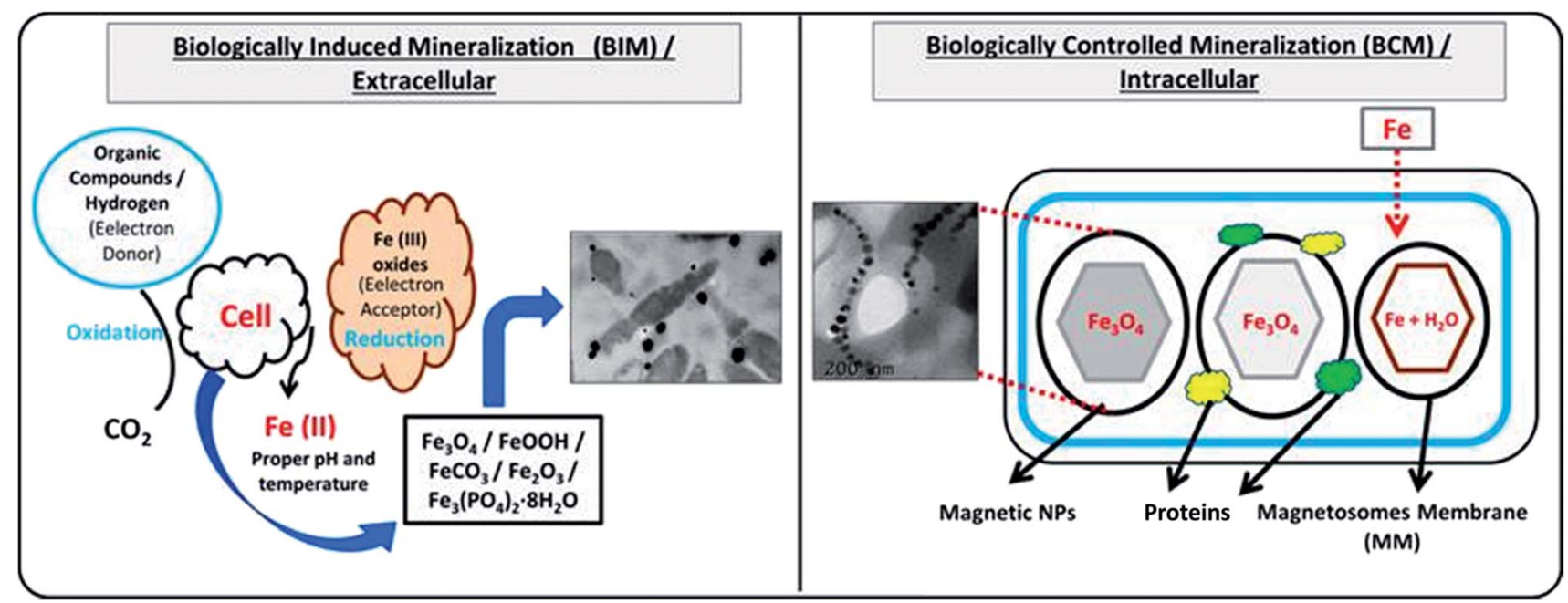

Fig. 3 Fabrication of biogenic magnetic nanoparticles (BMNPs) by biologically induced (BI) and biologically controlled (BC) mineralization processes.

Fig. 3 depicts that two biological processes i.e. Biological Induced Mineralization (BIM) and Biologically Controlled Mineralization (BCM), which are well known for the synthesis of biogenic MNPs. In BIM, bacterial cell wall/membrane filtrate is treated with metal ions solution keeping in the shaker in dark at room temperature and pressure and NPs are formed as a result of oxidation and reduction process. ${ }^{7}$ However in BCM, BMNPs are formed into the cells under well-defined condition and the nucleation and growth of the NPs are completely controlled by the organisms. ${ }^{4}$ This is the reason; the BMNPs synthesized by BCM processes are better in shape and size distribution than BIM process. ${ }^{26}$ Both types of BMNPs have been employed in the removal of pollutants and recovery of metals for industrial reuse. The well-known magnetotactic bacteria (MTB) are produced magnetosomes (MS) via BCM process, have been utilized in the removal and recovery of metals ions from industrial effluents..$^{30-33}$ MTB have shown superior performance than others MNPs because MTB can be easily separated from final effluents just using its naturally available magnetic nature. However, some challenging aspects such as isolation, characterization, well-defined culture preparation requirements e.g. oxygen, $\mathrm{pH}$, temperature, nutrients, iron supply and yield production are mainly hampered for it practical applications. ${ }^{1,34-37}$ Hence, it was our need to discover an alternate approach to fabricate MNPs using plants via green nanotechnology. Moreover, plant based fabrication of biogenic MNPs (i.e. PMNPs) is simple, clean, non-toxic, environmental friendly and bulk amount of NPs can be manufactured using minimum raw materials. The biomolecules (polyphony, aldehyde, carboxyl and amino acids groups) in plant extracts can be performed as both reducing and capping agents during fabrication. ${ }^{38}$ These biomolecules might be helpful in reducing pollutants strength and can be separated from final effluents via using magnet. ${ }^{4}$ The potential application of the PMNPs in environmental nanobiotechnology particularly in WWT could resolve nanotechnology implementation problems. ${ }^{7}$

\section{Fabrication of PMNPs using plants}

The concept of green chemistry was started in 1998 by introducing clean, non-toxic and environmental friendly reducing and capping agents (e.g. polyphenols, amino acids, sugars, alkaloids, terpenoids, proteins, carbonyl, carboxyl, polysaccharides) from plants and/or plants' part instead of highly harmful chemicals which were already being used for synthesizing NPs. ${ }^{1,16}$ Moreover, the objective of green chemistry is to use bio based resources under room temperature and pressure by minimizing experimental and environmental risks. ${ }^{35}$ In green nanotechnology, the choice of green alternative reducing, capping and stabilizing agents are the main important factors which make synthesis protocol clean and environmental friendly. Capping agents play a vital role in the fabrication of NPs because NPs can be modified in term of shape and size by manipulating properties of surfactants there by avoiding aggregation. However, these were difficult to remove and did not easily degrade that was increasing environmental risks. In contrast, in green nanotechnology, biomolecules (such as amino acids, polyphony, aldehyde and polysaccharides) are acting as capping and reducing agents which can be easily removed and separated from final effluents. This quality makes green nanotechnology superior than others technologies. Further, Fig. 4 shows the facts that there is an increasing research interest from last few years on the fabrication and application of PMNPs in WWT. Furthermore, the novel fabrication of BMNPs is also reported and protected by various U.S. Pat. e.g. 8,167,973(2012), ${ }^{39} 8,574,337(2013),{ }^{40} 8,790,615(2014),{ }^{41}$ $8,753,603(2014),{ }^{42} \quad 8,920,688(2014),{ }^{43} \quad 9,169,139(2015),{ }^{44}$ and $9,095,837(2015) \cdot{ }^{45}$

\subsection{Fabrication mechanisms}

Different types of plant metabolites (e.g. polyphenols, amino acids, sugars, alkaloids, terpenoids, proteins, carbonyl, carboxyl, and polysaccharides) act as an important bio-reducing 


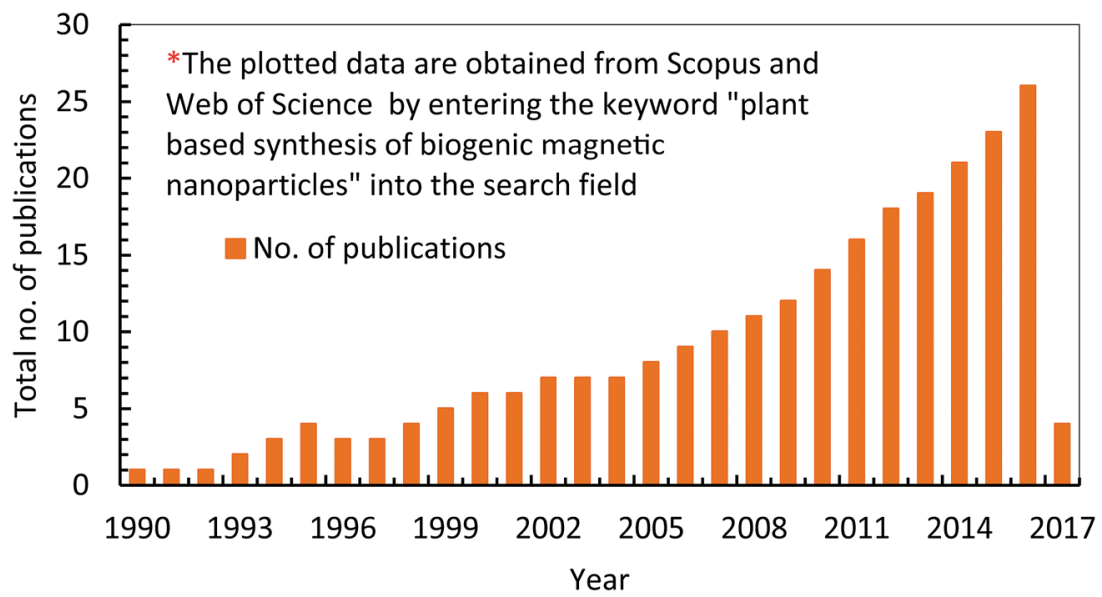

Fig. 4 Research developments about the fabrication and applications of phytogenic magnetic nanoparticles (PMNPs) in wastewater treatment (WWT).<smiles>CCCCOCCOCCOCCOC(=O)c1cc(O)c(O)c(O)c1</smiles><smiles>CC(C)(C)C(C)(C)OCC(O)C(O)C(O)C(O)C=O</smiles><smiles>O=C(O)C1O[C@H](O)[C@H](O)[C@H](O)[C@H]1O</smiles>

Polysaccharide<smiles></smiles>

Amino acid<smiles>[2H]C([2H])=O</smiles>

Carbonyl<smiles>Cn1c(=O)c2c(ncn2C)n(C)c1=O</smiles>

Caffeine

Fig. 5 Chemical structures of some plant metabolites commonly used in the fabrication of phytogenic magnetic nanoparticles (PMNPs).

agents for metallic ions, resulting in the formation of PMNPs of $\mathrm{FeO}, \mathrm{Fe}_{2} \mathrm{O}_{3}$, and $\mathrm{Fe}_{3} \mathrm{O}_{4}$. The chemical structures of some commonly used reducing and capping agents are shown in Fig. 5. In the starting phase, metal ions solution (e.g. $\mathrm{FeCl}_{3^{-}}$ $\left.\cdot 6 \mathrm{H}_{2} \mathrm{O} / \mathrm{FeSO}_{4} \cdot 7 \mathrm{H}_{2} \mathrm{O} / \mathrm{FeCl}_{2} \cdot 4 \mathrm{H}_{2} \mathrm{O} / \mathrm{Fe}\left(\mathrm{NO}_{3}\right)_{3}\right)$ as a precursor and plant extract as a reducing and capping agents are mixed alongwith sodium acetate as an electrostatic stabilizing agent in a flask by providing proper temperature with continues stirring. ${ }^{46-48}$ Thus, metal ions reduction will occur (such as $\mathrm{Fe}^{3+}$ to
$\mathrm{Fe}^{0}$ or $\mathrm{Fe}_{2} \mathrm{O}_{3} / \mathrm{Fe}_{3} \mathrm{O}_{4}$ ) due to the involvement of reducing and capping agents of plant metabolites. Meanwhile free radicals (R: -OH-group) will produce by the oxidation of plant residues, which will capable of further oxidation (Fig. 6). In the following phase, free radicals (-OH-group) will overlap with metal ions $(\mathrm{M}+)$ and will generate reduced metal atoms. ${ }^{49-52}$ The growth of these atoms will propagate and consequently, green nano zero valent iron (nZVI) or iron oxide $\left(\mathrm{Fe}_{3} \mathrm{O}_{4}\right)$ will form depending upon the fabrication condition. In the next phase, nucleation 


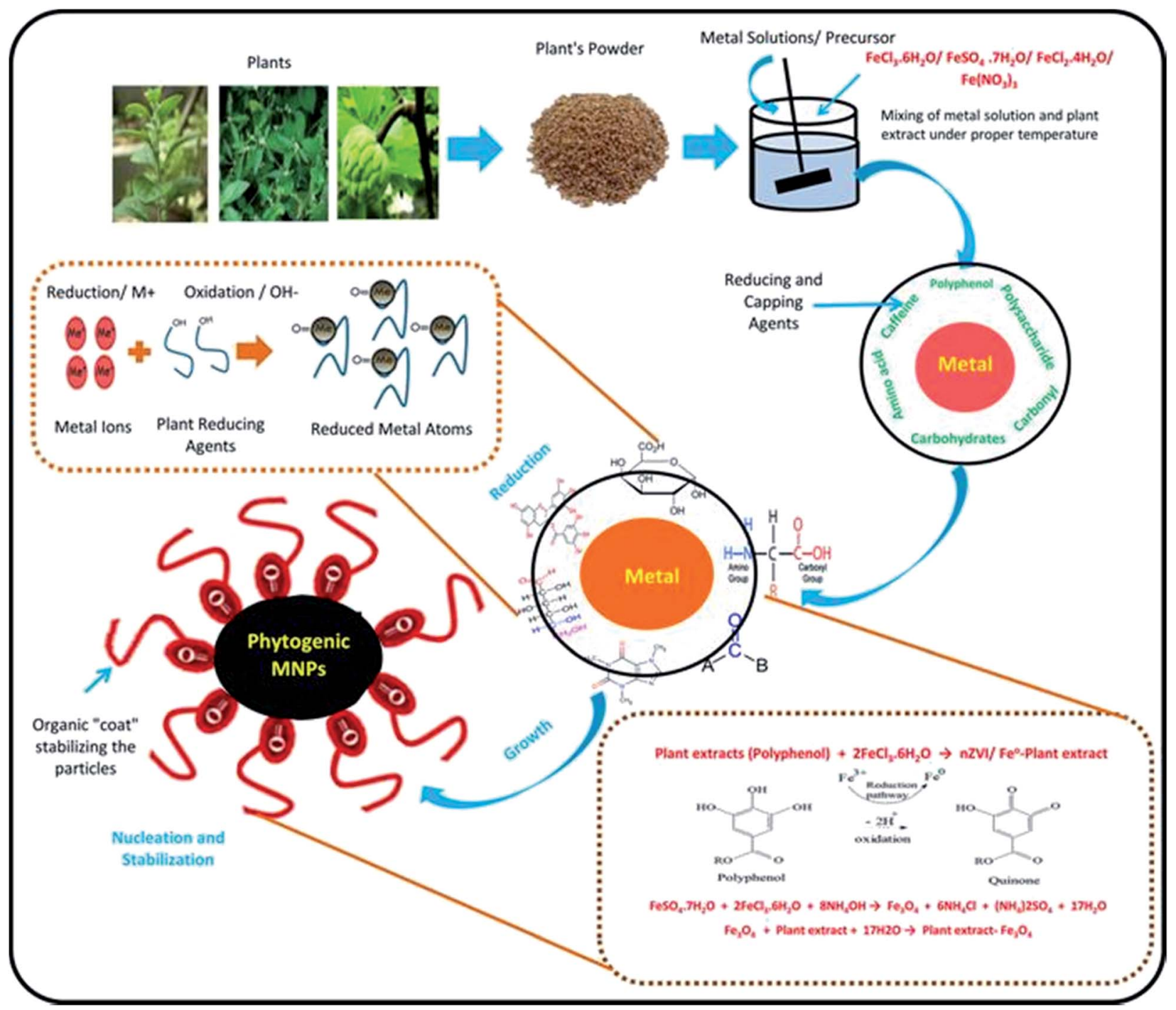

Fig. 6 Fabrication mechanism of plants based phytogenic magnetic nanoparticles (PMNPs).

and stabilization will occur, where organic molecules will act as coating agent and will stabilize particles till maturity in term of shape and size. Finally, black color precipitation will form indicating the fabrication of PMNPs. These precipitates are separated from solution by applying magnetic field or using simple filtration technique and then cleaned using solvent and dry in a vacuum oven for further applications. ${ }^{15,53,54}$ The general equations explaining the mechanisms of PMNPs fabrication are presented by via eqn (i)-(iii). ${ }^{\mathbf{1 , 3 , 1 8 , 5 5}}$

Plant extracts (polyphenol) $+2 \mathrm{FeCl}_{3} \cdot 6 \mathrm{H}_{2} \mathrm{O} \rightarrow$ $\mathrm{nZVI} / \mathrm{Fe}^{0}$-plant extract

$$
\begin{aligned}
\mathrm{FeSO}_{4} \cdot 7 \mathrm{H}_{2} \mathrm{O}+2 \mathrm{FeCl}_{3} \cdot 6 \mathrm{H}_{2} \mathrm{O}+8 \mathrm{NH}_{4} \mathrm{OH} \rightarrow \\
\mathrm{Fe}_{3} \mathrm{O}_{4}+6 \mathrm{NH}_{4} \mathrm{Cl}+\left(\mathrm{NH}_{4}\right)_{2} \mathrm{SO}_{4}+17 \mathrm{H}_{2} \mathrm{O}
\end{aligned}
$$

$\mathrm{Fe}_{3} \mathrm{O}_{4}+$ plant waste $+17 \mathrm{H}_{2} \mathrm{O} \rightarrow$ plant waste- $-\mathrm{Fe}_{3} \mathrm{O}_{4}$

\subsection{Factors affecting formation of PMNPs}

Table 1 depicts the summary of green fabrication of PMNPs using different plant/plant's parts with useful information. The general fabrication protocol of PMNPs is shown in Fig. S1. $\dagger$ It can be noticed that different kind of plants and plant wastes can be utilized for fabrication. The morphology and magnetic properties are also varying with respect to plant, precursor and applied conditions. ${ }^{\mathbf{8}, 9}$ There are certain aspects which can affect the formation of PMNPs such as types of plant/plant's part, mixing concentration, incubation temperature, contact time and $\mathrm{pH}$. Furthermore, these aspects can change morphology and ability of magnetisms. However, very little research effort is available which can address these aspects. Mainly, it can be observed that researchers are just focusing on the use of different plants for the formation of PMNPs (Table 1).

4.2.1 Temperature. Some research groups have tried to address the above discussed aspects. For example, Phumying et $a .^{49}$ conducted a study using Aloe vera plant extract and 


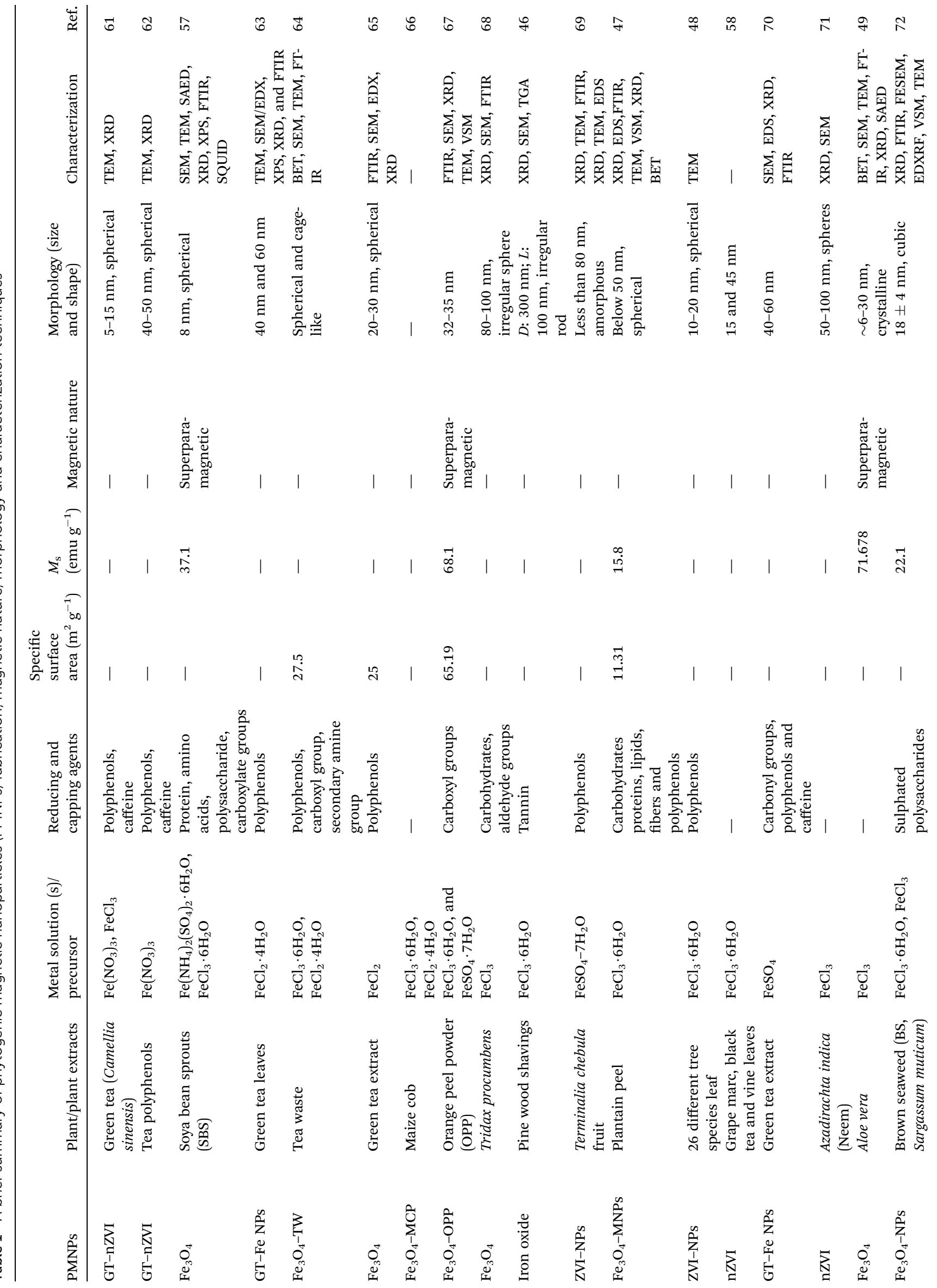




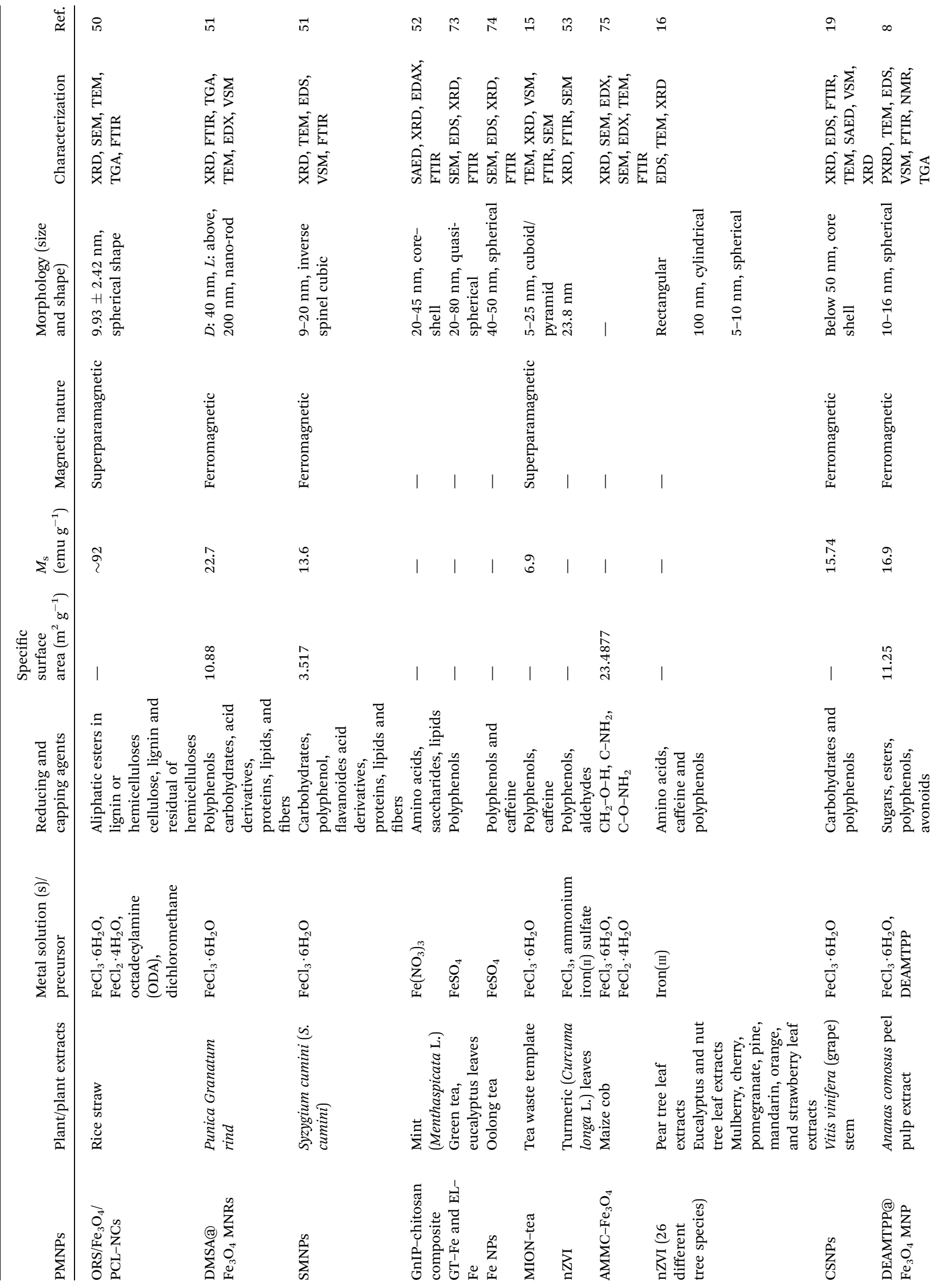




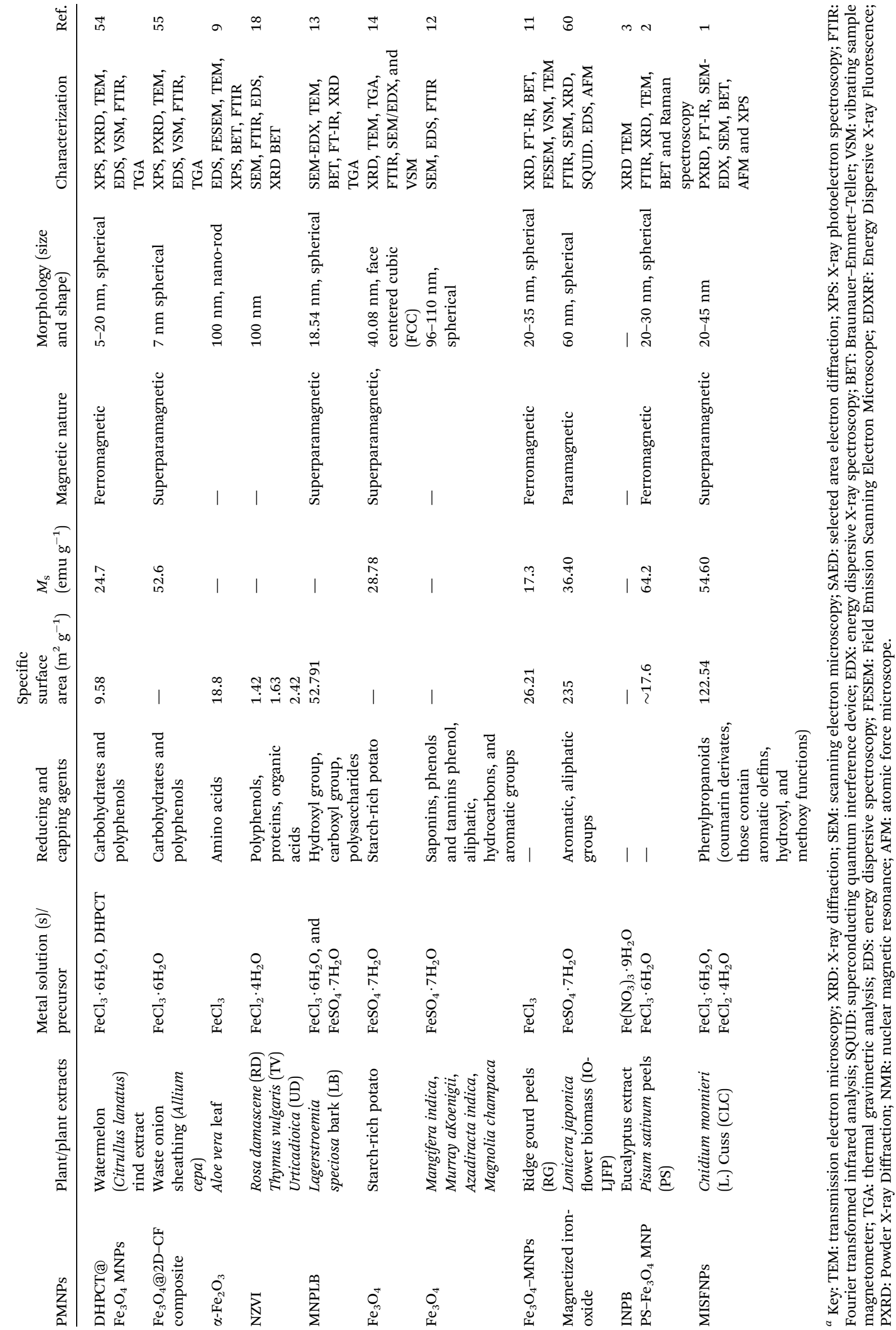




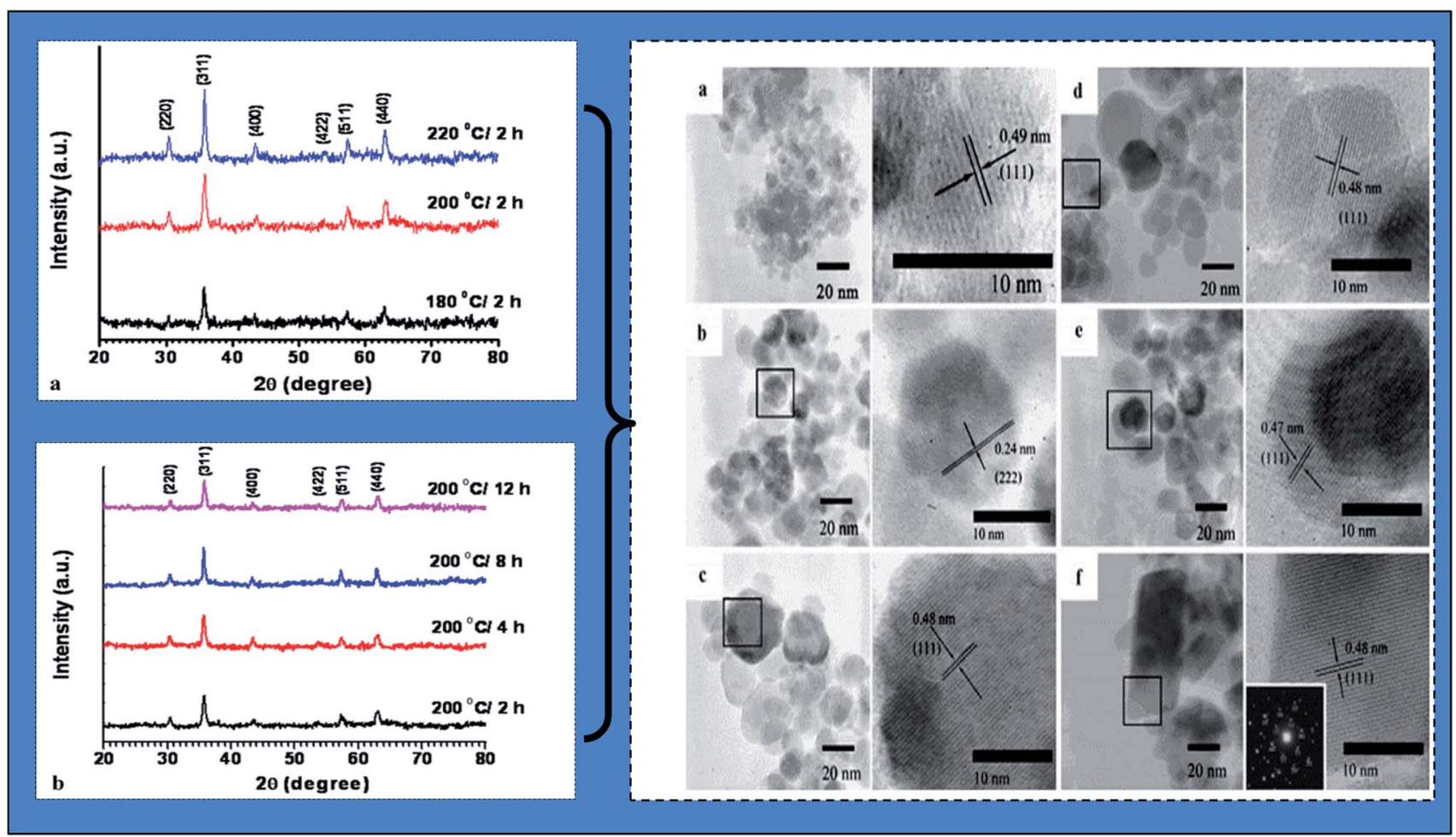

Fig. 7 X-ray diffraction (XRD) analysis patterns of fabricated biogenic magnetic nanoparticles (BMNPs) using Aloe vera plant-extracted solution (under (a) different hydrothermal temperatures and (b) different hydrothermal times) and high resolution transmission electron microscopic (TEM) images under different hydrothermal time and temperature: (a) $180{ }^{\circ} \mathrm{C} / 2 \mathrm{~h}$; (b) $200{ }^{\circ} \mathrm{C} / 2 \mathrm{~h}$; (c) $220{ }^{\circ} \mathrm{C} / 2 \mathrm{~h}$; (d) $200{ }^{\circ} \mathrm{C} / 4 \mathrm{~h}$; (e) $200{ }^{\circ} \mathrm{C} / 8 \mathrm{~h}$; and (f) $200^{\circ} \mathrm{C} / 12 \mathrm{~h}$ (reproduced from Phumying et al. ${ }^{49}$ Copyright@2012, with permission from Springer).

investigated influence of reaction temperature and contact time on the fabrication of PMNPs. The results indicated that saturation magnetization of the PMNPs was increased from 56.313 emu $\mathrm{g}^{-1}$ to $71.678 \mathrm{emu}^{-1}$ by increasing temperature and contact time from $180{ }^{\circ} \mathrm{C} / 2 \mathrm{~h}-200{ }^{\circ} \mathrm{C} / 12 \mathrm{~h}$ as shown in Fig. 7 . Similarly, morphology of the fabricated PMNPs was also varied. In contrast, Demir et al..$^{56}$ conducted a study to optimize influence of temperature on the saturation magnetization of PMNPs using products of maltose putrefaction e.g. glucose and glucomicacide as reducing and capping agent respectively and reported that by increasing temperature saturation magnetization $\left(M_{\mathrm{s}}\right)$ of the PMNPs were decreased. However, PMNPs were showing super paramagnetic behavior along-with $43.06 \mathrm{emu} \mathrm{g}^{-1}$ of $M_{\mathrm{s}}$ at room temperature. Zero field cooled and field cooled magnetization analysis was also employed for optimization, and blocking temperature (TB) was found at $74 \mathrm{~K}$. The results indicated that above and below this temperature $M_{\mathrm{S}}$ of the PMNPs was decreasing by increasing or decreasing applied temperature. Similarly, in another study conducted by Cai et al..$^{57}$ using Soya bean sprouts (SBS) and reported blocking temperature (TB) at $150 \mathrm{~K}$ and $M_{\mathrm{S}}$ of $37.1 \mathrm{emu} \mathrm{g}^{-1}$. However, fabricated PMNPs were showing super paramagnetic behavior at room temperature.

It is well known fact that, for adsorption of toxic pollutants, adsorbent should have super paramagnetic in nature with high value of $M_{\mathrm{s}}$. If an adsorbent is super paramagnetic in nature, then there will be no attraction and repulsion among the particles in the absence of an external magnetic force, which mean a zero moment will exist in the absence of an applied external magnetic field and thereby will help during separating adsorbent from final effluent. If higher the $M_{\mathrm{s}}$ value then it will give excellent response to applied external magnetic field, which eventually will minimize the applied external magnetic energy and operational cost of the treatment system.

4.2.2 Types of plant/plant's part. Machado et al. ${ }^{58}$ reported the optimization of fabrication of PMNPs protocol. Initially, the research investigators conducted a detail study to optimize fabrication protocol using 26 trees leaf extracts and determined antioxidant capacity by varying leaf mass concentration, temperature, contact time, moisture content and solvent ratio. The results indicated that each element had influenced on the fabrication and antioxidant capacity. For example, dry leafs were showing higher antioxidant capacity than natural leaf. In case of solvent, comparatively water can be used as a solvent which will minimize manufacturing cast. In case of temperature and contact time, each leaf was showing different antioxidant capacity at same temperature and contact time, however all the extraction showed best results at maximum temperature of $80{ }^{\circ} \mathrm{C}$ using $20 \mathrm{~min}$ of contact time. On the other side, by increasing leaf mass and solvent volume ratio, antioxidant capacity was also increasing. Fig. 8 depicts that each tree leaf had different phenolic content thereby antioxidant capacity of the every tree leaf will be different. The results indicated that if higher the phenolic content then higher will be antioxidant 


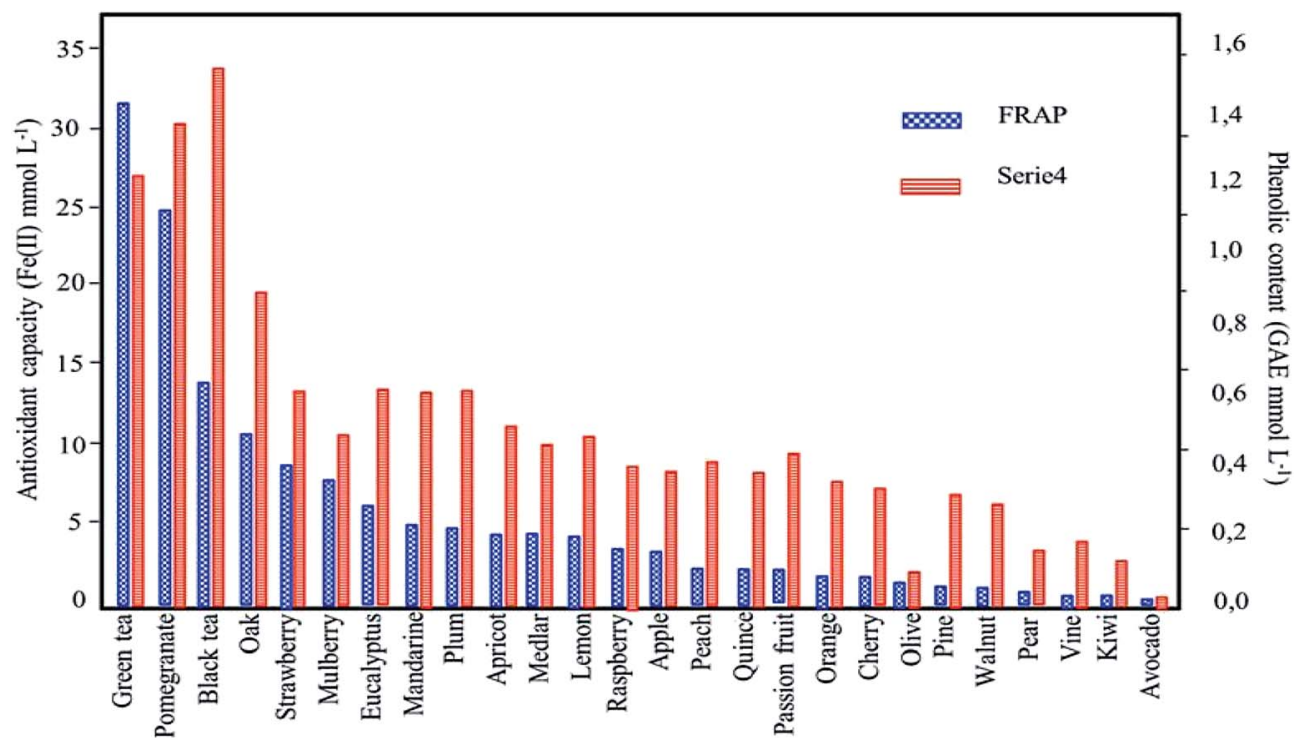

Fig. 8 Influence of phenolic content/plant metabolites on the antioxidant capacity: results obtained by comparing Ferric reducing antioxidant power (FRAP) and Folin-Ciocalteu methods (reproduced from Machado et al. ${ }^{48}$ Copyright@2013, with permission from Elsevier).

capacity. Later on, same research group also reported similar findings and concluded that morphology, antioxidant capacity, reactivity and agglomeration tendencies varied from plant to plant and by alteration of PMNPs fabrication protocol. ${ }^{\mathbf{1 0}}$

4.2.3 pH. The $\mathrm{pH}$ of the plant extract have also influence on the morphology and antioxidant capacity. Normally it is noticed that $\mathrm{pH}$ of the solution decrease during fabrication of PMNPs. It may effect the metal ions reduction which may effect the morphology and yield production of PMNPs. ${ }^{59}$ Particularly regarding $\mathrm{pH}$, there is no information available in the literature which can address pH influence on PMNPs fabrication using plant species. Many studies revealed that different plants act

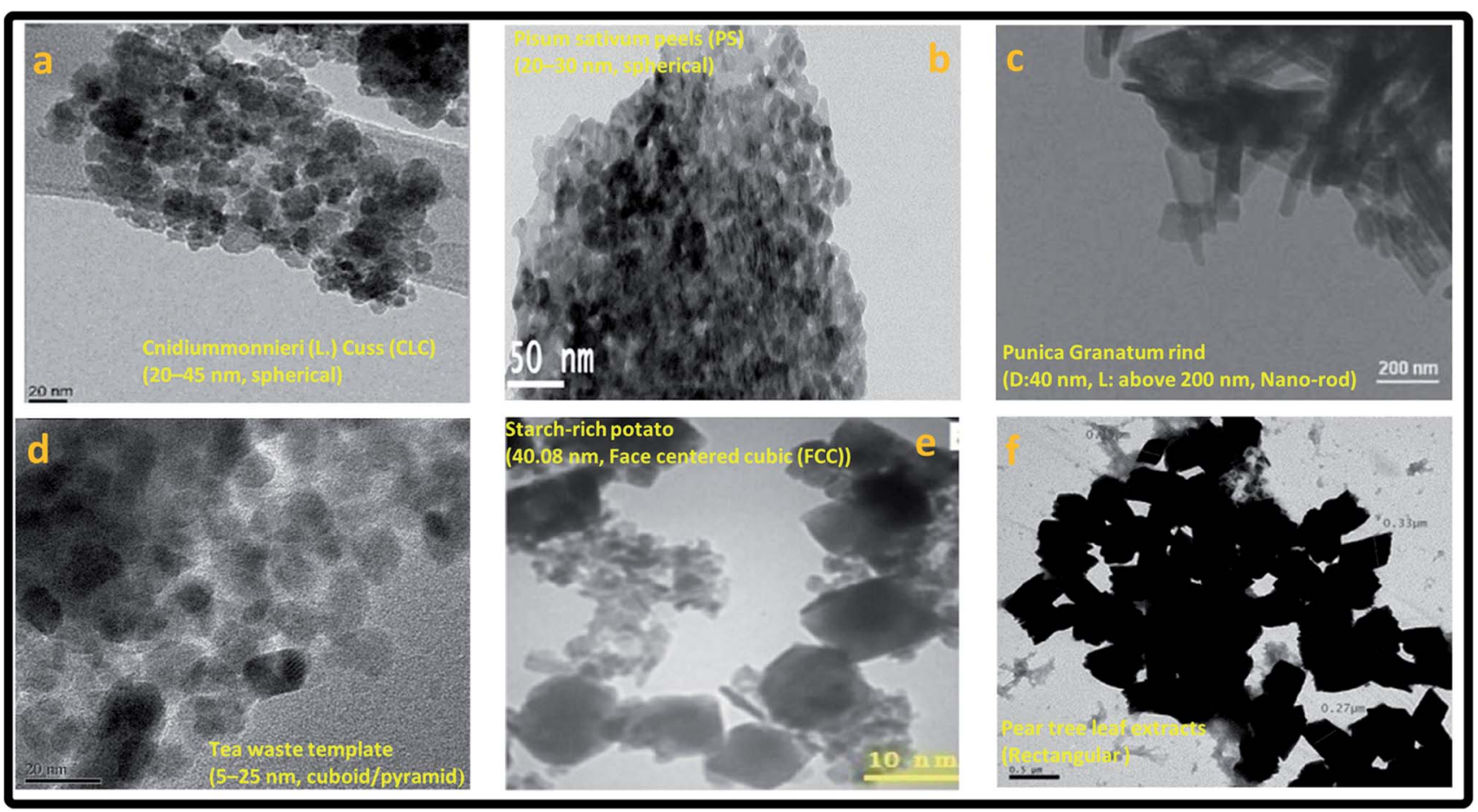

Fig. 9 Transmission electron micrograph (TEM) showing morphology of the phytogenic magnetic nanoparticles (PMNPs), reproduced from (a) Lingamdinne et al., ${ }^{1}$ Copyright@2017, with permission from Elsevier (b) Prasad et al., ${ }^{2}$ Copyright@2017, with permission from Elsevier (c) Venkateswarlu et al., ${ }^{17}$ Copyright@2014, with permission from King Saud University and Elsevier, (d) Lunge et al., ${ }^{15}$ Copyright@2014, with permission from Elsevier (e) Buazar et al., ${ }^{14}$ Copyright(a2016, with permission from John Wiley and Sons (f) Machado et al., ${ }^{16}$ Copyright@2015, with permission from Elsevier. 
differently during fabrication of PMNPs due to the presence of different biomolecules. ${ }^{16}$ In most of the studies, Fourier transform infrared spectroscopic (FTIR) results indicated that $\mathrm{O}-\mathrm{H}$ stretching vibrations (of polyphenolic group), $\mathrm{C}-\mathrm{H}$ stretching vibration (of methyl and methoxy groups), C-O stretching vibration (of acid derivatives), $\mathrm{C}=\mathrm{O}$ group (of the aliphatic esters), $\mathrm{C}=\mathrm{O}$ group (of carboxylic acids and aliphatic esters) and others group of biomolecules were the main elements for the formation of PMNPs. Hence, the morphology and reactivity of the PMNPs against targeted pollutant may vary due to presence of different biomolecules in different plants., ${ }^{\mathbf{1 , 2 , 1 1 - 1 4 , 6 0}}$

Therefore, it can be concluded from these studies that plant antioxidant capacity, $M_{\mathrm{s}}$, reactivity, and magnetic behavior could be varied by manipulating fabrication protocol such as temperature, $\mathrm{pH}$, contact time, type of solvent, plant extract concentration and metal ions solution concentration.

Furthermore, desire quality of PMNPs was fabricated using minimum cost and energy by optimizing manufacturing procedure (Fig. 9). Thus, more research efforts are needed to address this aspect.

\section{Removal of aqueous pollutants using PMNPs}

PMNPs fabricated from different types of plant species have been employed for the removal of heavy metals, toxic textile dyes, pigments, pharmaceutical and personal care products (PPCP), pesticides and organic pollutants from domestic wastewater. , $^{\mathbf{3 , 1 3}, \mathbf{1 8 , 5 5 , 6 0}}$ Due to the superior performance, PMNPs have been used as noble adsorbents. ${ }^{76}$ However, other aspects such as reusability, biomass separation, metals recovery, regeneration were rarely explored. But some research groups were activity involved on the examination of PMNPs reusability, biomass separation and resource recovery. ${ }^{\mathbf{1 , 3 , 1 3 , 5 5 , 6 0}}$ Therefore, herein, we are proposing very first time a model of PMNPs based zero effluent discharge WWT using plant metabolites as reducing and capping agents (Fig. 10).

\subsection{Performance of PMNPs}

Adsorption process has been used for investigating removal performance and mechanisms in most of the research studies, because rate-controlling step in the adsorption presents intimation to understand removal mechanism. ${ }^{1}$ Thus, different types of adsorption isotherm (Langmuir, Freundlich and D-R) and kinetic (pseudo first order, pseudo second order, WeberMorris, Elovich and Boyd's) models were used and results were compared using linear regression correlation coefficient $\left(R^{2}\right)$ values. ${ }^{55}$ The literatures showed that pseudo second order kinetic model and Langmuir isotherm was best fitted with adsorption kinetic and isotherm data in most of the reports (Table 2). These findings depicted that mainly removal support the assumption of adsorption was chemisorption and exposing that functional groups from plant metabolites (hydroxyl, carboxyl, amino, etc.) were playing major role in the adsorption removal of pollutant via electrostatic interactions and ion exchange process. ${ }^{\mathbf{1 , 1 3 , 1 8 , 5 5 , 6 0}}$ In contrast, few studies supported pseudo first order and Boyd's model, presenting fact that adsorption might be due to intraparticle diffusion or chemical monovalent ion exchange..$^{3,64,70,73,74}$ On the other hand, regarding adsorption isotherm data, almost all of the studies supported Langmuir model and indicating the assumption of monolayer adsorption of pollutants/adsorbates on a solid surface. ${ }^{1,15,17,54}$

Numerous researchers and research groups have reported adsorptive removal of toxic heavy metals such as $\mathrm{Cr}(\mathrm{III}), \mathrm{Pb}(\mathrm{II})$,

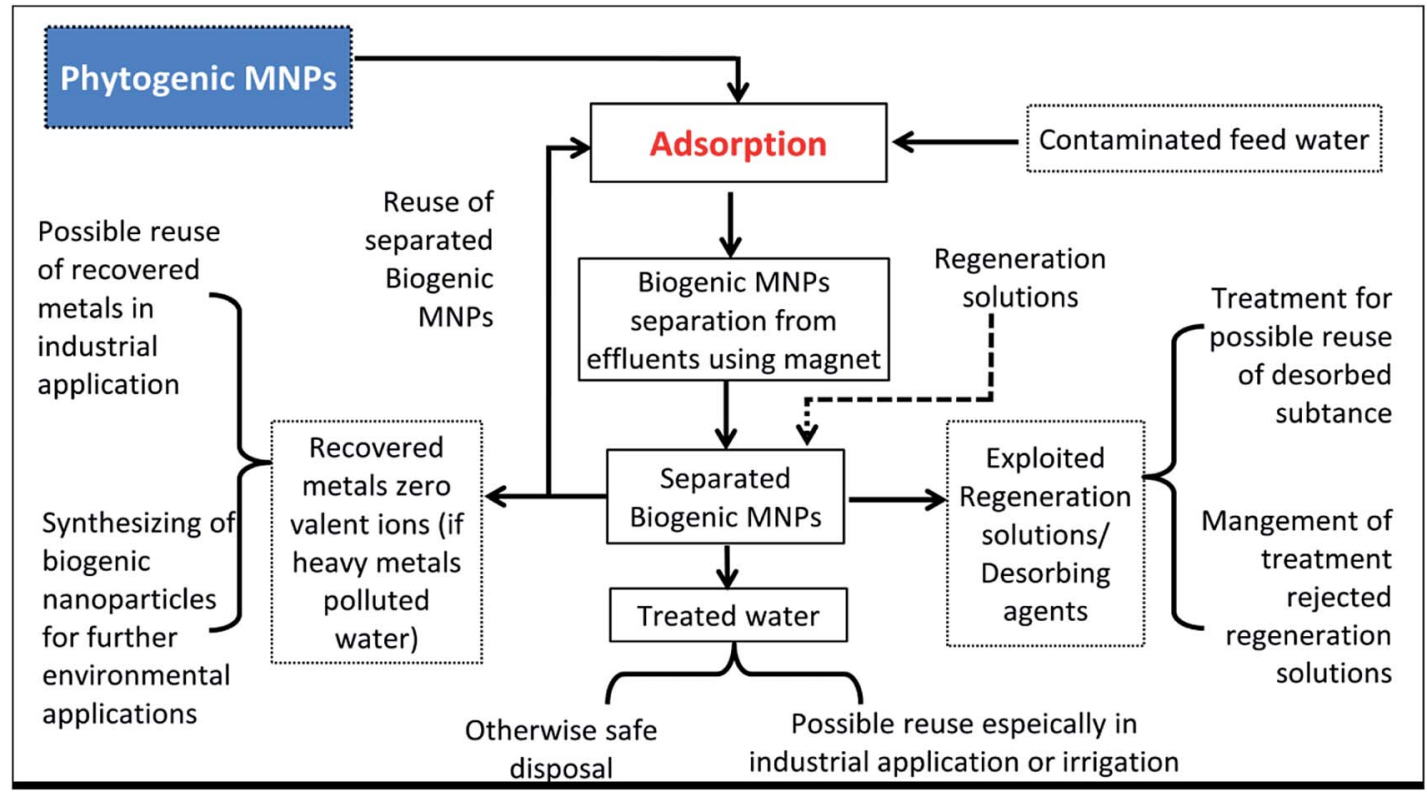

Fig. 10 Schematic of our proposed phytogenic magnetic nanoparticles (PMNPs) based zero effluent discharge water/wastewater treatment (WWT) process. 


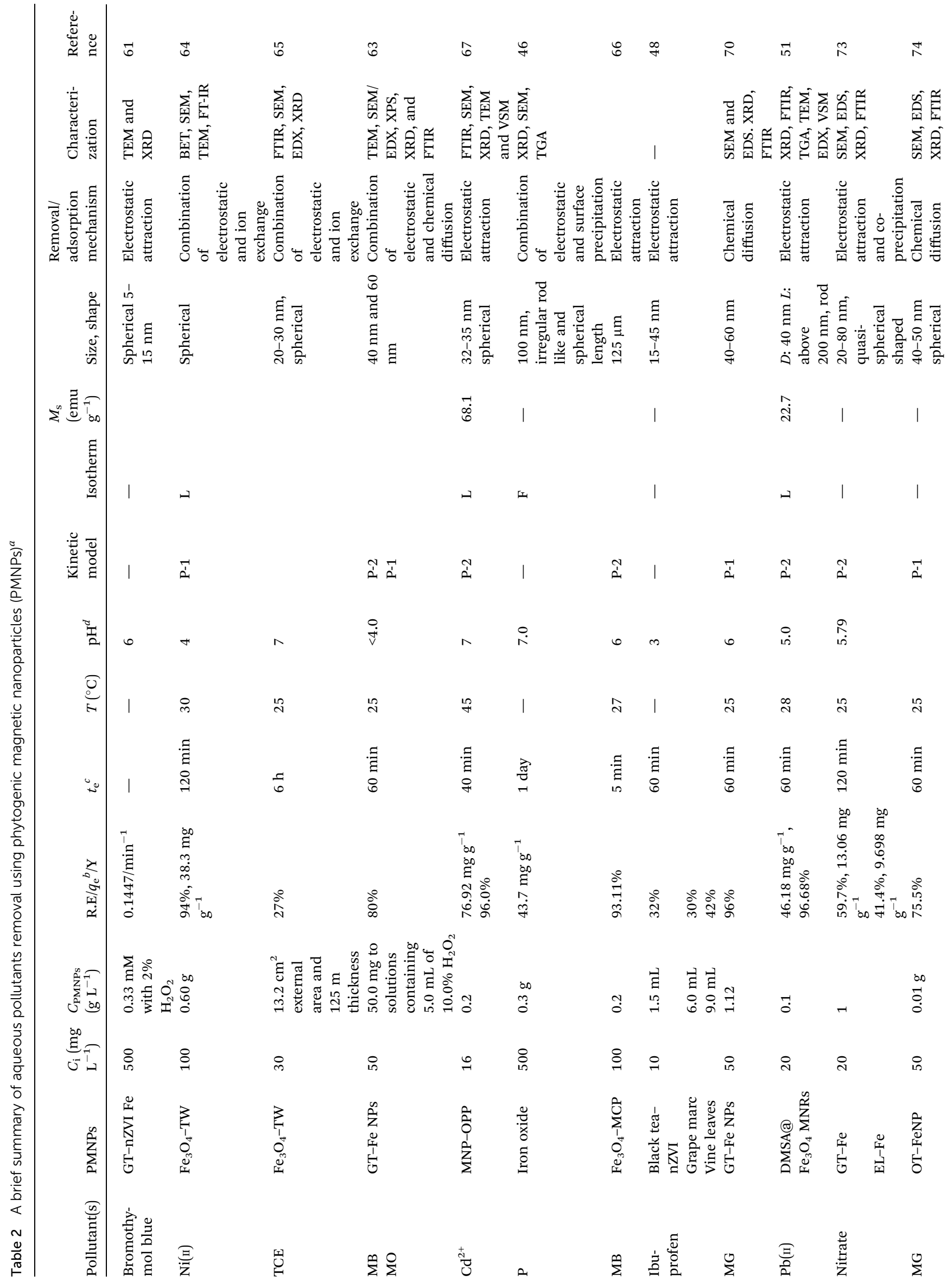




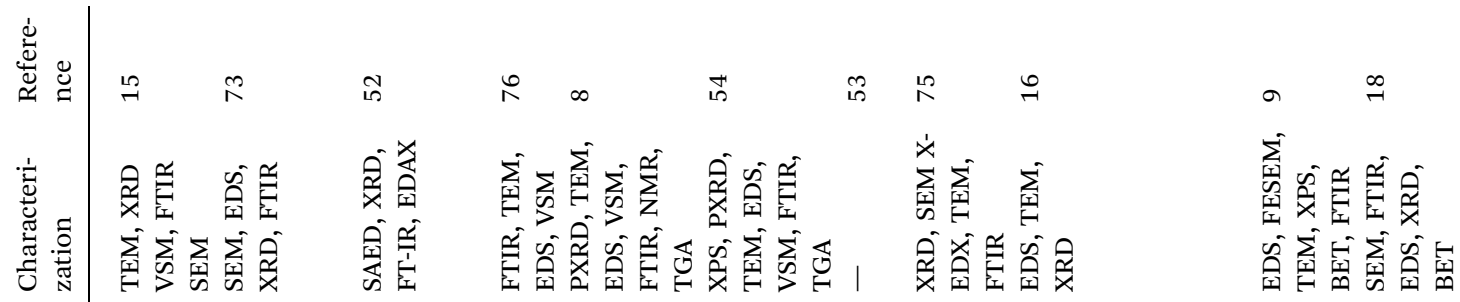

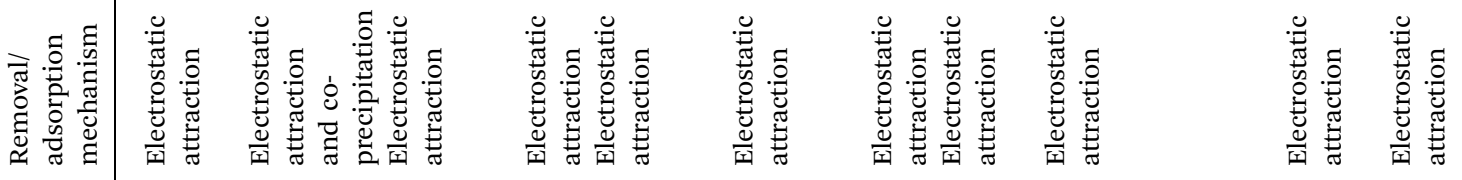

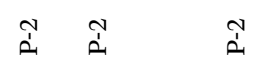

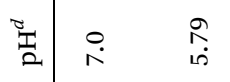

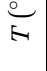

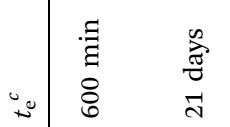

:
品

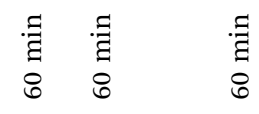

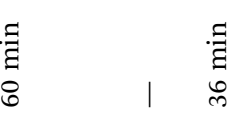

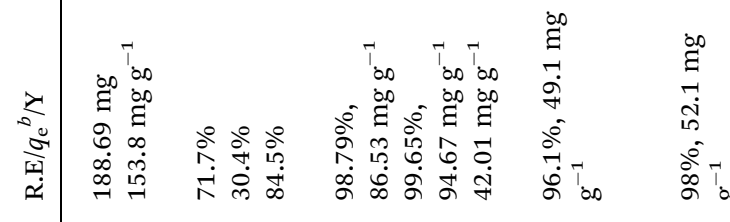

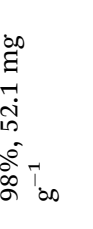

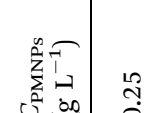

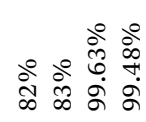

ஓे के

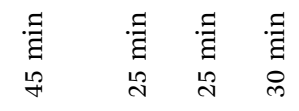

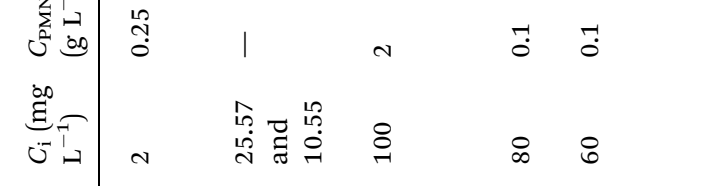

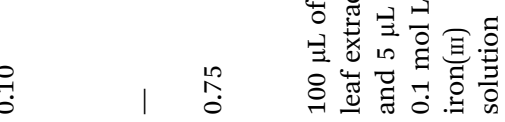

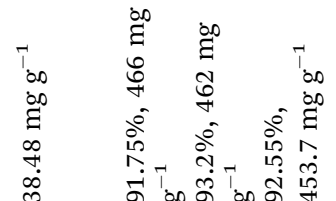




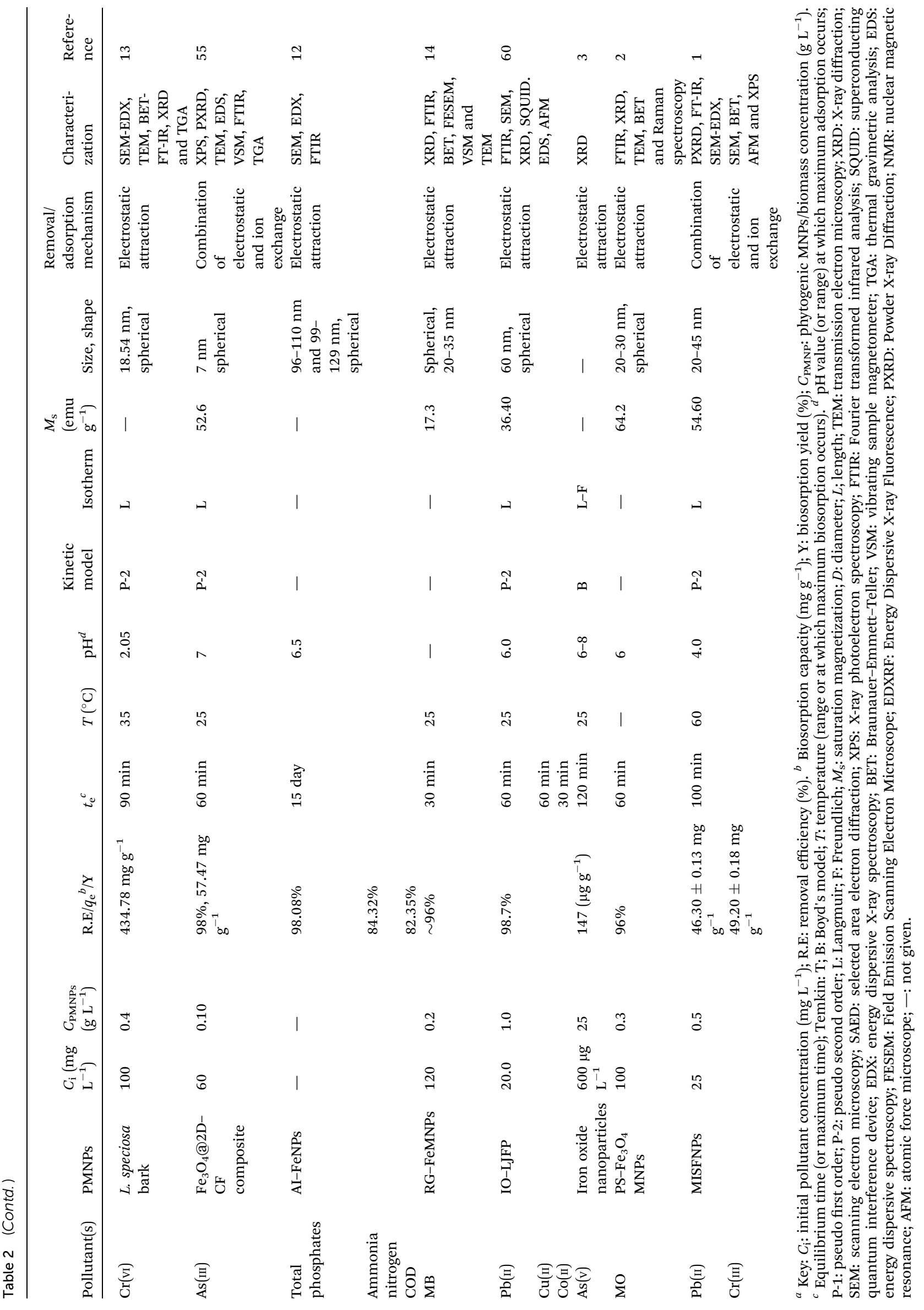


$\operatorname{As}(\mathrm{v}), \mathrm{Co}(\mathrm{II}), \mathrm{Cu}(\mathrm{II}), \mathrm{As}(\mathrm{III}), \mathrm{Cr}(\mathrm{VI}), \mathrm{Hg}(\mathrm{II}), \mathrm{Ni}(\mathrm{II}), \mathrm{Cd}^{2+}$ using PMNPs (Table 2). The findings depicted that removal was due to the presence of specific functional groups in the shape of reducing and capping agents of plant metabolites that had charge opposite to metallic ions.

Mainly-OH-groups were actively participated in the removal of metallic ions via ion exchange and electrostatic attraction process. ${ }^{1,17,18,54,60}$ However, it was also fact that removal or reactivity of the various types of PMNPs fabricated from different plant species showed diverse adsorptive removal against same metallic ion due to the capability of specific functional group and the presence of different plant metabolites.

Despite this fact discussed above, maximum adsorptive capacity and removal for each heavy metal was achieved using Langmuir isotherm model (Table 2). For example in case of As(III), a maximum of $98 \%$ removal and $57.47 \mathrm{mg} \mathrm{g}^{-1}$ of adsorptive capacity was achieved within 60 min just using $0.10 \mathrm{~g} \mathrm{~L}^{-1}$ of adsorbent quantity and biomass/adsorbents were rapidly separated using magnet within $28 \mathrm{~s} .^{55}$ These studies evidenced that adsorption process was mainly dependent upon the charge of the functional groups and adsorbate. Toxic textile dyes and pigments have been also removed using PMNPs (Table 2).

Some researchers reported that PMNPs depicted superior performance in degrading and as well as in adsorptive removal of toxic dyes. ${ }^{2}$ Panneerselvam et al. ${ }^{64}$ compared PMNPs performance with Fe-EDTA and Fe-EDDS by taking pigments (bromothymol blue) as a representative toxic dye and reported better degradation rate of $0.144 / \mathrm{min}^{-1}$ using dosage of $0.33 \mathrm{mM}$ with $2 \% \mathrm{H}_{2} \mathrm{O}_{2}$ than Fe-EDTA and Fe-EDDS. The findings showed that PMNPs were better catalyst in producing free radical from $\mathrm{H}_{2} \mathrm{O}_{2}$ which eventually increased degradation performance.

Most of the researchers reported adsorptive removal of methylene blue (MB) and methyl orange (MO) using PMNPs (Table 2). PMNPs were utilized by mixing $5 \mathrm{~mL}$ of $\mathrm{H}_{2} \mathrm{O}_{2}$ for the adsorptive removal of $\mathrm{MB}$ and $\mathrm{MO}$ and results were compared with chemically fabricated NPs. The findings revealed that PMNPs were more effective and indicating Fenton-like catalysts performance than chemically synthesizing MNPs. It is also worth mentioning that the adsorptive removal was increased by decreasing $\mathrm{pH}$ of the system with respective to the addition $\mathrm{H}_{2} \mathrm{O}_{2}$ and decreased after $\mathrm{pH}$ 4. Furthermore, the dyes removal rates followed second and first order for $\mathrm{MB}$ and $\mathrm{MO}$ respectively.

In another study maize cobs powder were used for fabricating PMNPs and adsorptive removal of MB dye was reported by Tan et al. ${ }^{66,75}$ as illustrated in (Table 2). The findings depicted that mainly removal was due to electrostatic attraction of negative charge from PMNPs and cationic dyes and adsorbates/ pollutants were presenting monolayer adsorption on the surface of adsorbent (Table 2). Recently, Buazar et al. ${ }^{14}$ and Prasad et al. ${ }^{2}$ also reported that toxic dyes were removed due to the electrostatic interactions between PMNPs and cationic dyes (Table 2). These findings, therefore, depicts PMNPs had negative charge active sites due to the presence functional groups from plant metabolites which were creating electrostatic interaction forces for efficient removal of cationic dyes.
PMNPs were also utilized for the removal of organic pollutants from domestic wastewater (Table 2). Adsorptive removal and capacity of different organic pollutants such as total phosphorous (TP), ammonia nitrogen $\left(\mathrm{NH}_{3}-\mathrm{N}\right)$, chemical oxygen demand (COD), phosphates $\left(\mathrm{PO}_{4}{ }^{3-}\right)$, nitrate and malachite green (MG) were investigated by different researchers. ${ }^{\mathbf{1 2 , 4 6 , 6 0 , 7 3 , 7 5}}$ Ramasahayam et al. ${ }^{\mathbf{4 6}}$ found that phosphorus (P) was mainly adsorbed due to the combination of adsorption and surface precipitation mechanism and multilayer adsorption with random distribution was occurred. In contrast, MG adsorptive removal was occurred due to chemical diffusion mechanism in the solution and degradation was by the breakage of benzene ring bonds. ${ }^{70,74}$ However, Wang et al. ${ }^{73}$ conducted a study for the adsorptive removal of nitrate from domestic wastewater and investigated that nitrate adsorptive removal was occurred due to chemisorption mechanism (Table 2). Some other researchers investigated removal of $\mathrm{TP}$, ammonia nitrogen, $\mathrm{COD}$ and $\mathrm{PO}_{4}{ }^{3-}$ from domestic wastewater using PMNPs and reported maximum of $98.08 \%$ of TP, ${ }^{12} 84.32 \%$ of $\mathrm{NH}_{3}-\mathrm{N},{ }^{12} 99.63 \%$ of $\mathrm{COD}^{75}$ and $82 \%$ of $\mathrm{PO}_{4}{ }^{3-}$ removal. ${ }^{53}$ Moreover, to investigate the adaptability of PMNPs in large scale applications for environmental protection, some researchers used PMNPs in the removal of persistent or refractory organic pollutants, such as trichloroethylene (TCE) and Ibuprofen (Table 2). However removal performance was not so high. Hence, more research efforts are required to investigate PMNPs potential for these kinds of pollutants.

In summary, three types of removal mechanism were mainly reported depending upon chemical nature of pollutants and fabrication of PMNPs including, (i) chemisorptions mainly electrostatic attraction between cationic pollutants and opposite charge of MNPs due to presence of multifunctional groups from plant metabolites, (ii) ion exchange mainly due to $-\mathrm{OH}$ groups, and (iii) chemical diffusion between the particles in the solution mainly due to the breakage of functional ring bonds. ${ }^{74}$ In addition, Table 2 depicts also other important aspects of adsorption process which are mainly required to address system performance, such as pollutants concentration, dosage, reaction temperature, $\mathrm{pH}$ and contact time. In most of the studies, maximum adsorptive removal was achieved at neutral pH or below under approximately at room temperature.55,60 However, according to economical point of view, ideally, a system should be capable to remove pollutants over a wide $\mathrm{pH}$ range. In many studies, effect of $\mathrm{pH}$ was investigated and reported that maximum removal was supported at low $\mathrm{pH}$ range (4-6) and in some cases at $\mathrm{pH} \mathrm{7.54,73}$ It is also worth mentioning that $\mathrm{pH}$ could vary during treatment because of the organic nature of the reducing and capping agents. Normally, it is seen that extracts $\mathrm{pH}$ reduced during fabrication of PMNPs and this fact could also vary $\mathrm{pH}$ during treatment. Furthermore, neutral $\mathrm{pH}$ and room temperature is considered as an ideal according to economical point of view that can reduce chemical consumption for $\mathrm{pH}$ adjustment. However, if high $\mathrm{pH}$ is concern for specific pollutant, then PMNPs can be modified by manipulating fabrication protocol (e.g. by varying plant metabolites). 


\subsection{Effect of co-existing ions and multi pollutants}

Wastewater is often a complex mixture of different pollutants. ${ }^{53}$ For practical or real implementation of any technology, it is compulsory, particularly for domestic and industrial usage, to investigate performance of proposed technology under typical complex system. Thus, in the case of PMNPs, it was also necessary to check its effectiveness to remove specific pollutant under complex system. Because it is a common phenomenon that co-existing cationic, anionic and others pollutants often minimize removal performance via competing effect.

However, in case of PMNPs, the reported findings are different and surprising. In most of studies, it was observed that removal performance was sustained under complex system..$^{8,15,19,46,67,73}$ Venkateswarlu et al. ${ }^{19}$ compared nickel removal under the presence of co-existing ions $\left(\mathrm{Co}^{2+}, \mathrm{Na}^{+}, \mathrm{Ca}^{2+}\right.$, $\mathrm{K}^{+}$, and $\mathrm{Mg}^{2+}$ ) and reported more than 95\% removal by 3MPA@Fe $\mathrm{O}_{4}$ MNPs. The applied PMNPs showed high selectivity against nickel ions due to the strong bonding mercapto group with nickel ions rather than other ions according to Hard-Soft Acid-Base (HSAB) theory.

According to this Hard-Soft Acid-Base (HSAB) theory, interactions are normally predominated between soft acid and soft base in a complex system. Similarly, Venkateswarlu and Yoon $^{8}$ investigated $\mathrm{Cd}$ (II) ions removal in the presence of $\mathrm{Zn}$ (II), $\mathrm{Cu}(\mathrm{II}), \mathrm{Co}(\mathrm{II})$, and $\mathrm{Ni}(\mathrm{II})$ ions and observed maximum removal of Cd(II) ions without any interference due to co-existing ions. According to HSAB theory, Cd(II) was a soft acid which will preferably interact with soft base than other ions. Mainly selectivity was due to the presence of mercapto and amine groups on the PMNPs and Cd(II) interaction towards mercapto was higher than other ions due to the softness of the base. In another study, Venkateswarlu and Yoon ${ }^{54}$ reported more than 96\% of $\mathrm{Hg}$ (II) removal even in the presence of various competing ions (i.e. $\mathrm{Pb}(\mathrm{II}), \mathrm{Zn}(\mathrm{II}), \mathrm{Ni}(\mathrm{II}), \mathrm{Co}(\mathrm{II})$ and $\mathrm{Cu}(\mathrm{II})$ ). The composite showed much higher removal efficiency for $\mathrm{Hg}$ (II) ions than other metal ions in the following order: $\mathrm{Hg}$ (II) $\gg \mathrm{Co}$ (II) $>\mathrm{Zn}$ (II) $>$ $\mathrm{Cu}(\mathrm{II})>\mathrm{Pb}$ (II) $>\mathrm{Ni}$ (II). It was expected that the carbamodithioate $\left(\mathrm{CS}^{2-}\right)$ functional group plays a crucial role in the $\mathrm{Hg}$ (II)-selectivity due to the softness of the base. Moreover, Gupta et al. ${ }^{67}$ also reported about $82 \%$ of $\mathrm{Cd}(\mathrm{II})$ removal in the presence coexisting ions (nickel and zinc ions) using real wastewater from electroplating industry. However, in case of As(III), Lunge et al. ${ }^{15}$ reported increasing interference by increasing anions concentration $\left(\mathrm{NO}^{3-}, \mathrm{Cl}^{-}, \mathrm{PO}^{4-}\right.$ and $\mathrm{SO}_{4}{ }^{2-}$ ) and $\mathrm{AS}(\mathrm{III})$ removal was decreased by increasing anions concentration.

Moreover, selectivity performance of PMNPs also investigated using domestic wastewater by the numerous researchers and reported significant removal of organic pollutants such as $\mathrm{P}, \mathrm{N}$ and COD. ${ }^{46,73}$ Overall, mostly studies supported that different types of PMNPs were effective for specific pollutants removal and the selectivity of the specific pollutant removal mainly dependent upon the following aspects. (a) Availability of the functional groups on the surface of fabricated PMNPs (because different functional groups of plant metabolites possess different selectivity against different pollutants), (b) pollutant type and strength (acidic or basic in nature), and (c) availability of the active sites on the surface of fabricated PMNPs (because sometime pores filled due to pollutants adsorption). However, selective removal can be improved by manipulating functional groups and modifying fabrication protocol to increase active sites for specific pollutant(s) which eventually would increase reusability of the PMNPs.

\section{Regeneration and reusability of PMNPs}

PMNPs have proved superior potential in term of fabrication (safe, clean, non-toxic and environmental friendly) and higher removal performance. However, in nanotechnological point of view, particularly for nanoparticles application, regeneration and reusability is obligatory which directly influence on the treatment cost and technology sustainability. ${ }^{55}$ Furthermore, exhausted adsorbents are itself threat to environment. Therefore, an adsorbent should be capable that can regenerate and reuse for consecutive treatment cycle and or able can produce zero effluent. ${ }^{13}$ Moreover, it is considered that PMNPs have ability to produce zero effluent owing to the presence of organic functional groups on the surface of adsorbent which could eventually degrade after certain period of time. ${ }^{15}$ However this aspect can also minimize reusability particularly in term of adsorption process. In few studies, regeneration and reusability of PMNPs have been investigated and a brief summary of the results is provided in Table 3. Most of the studies showed that adsorption and desorption performance was up-to five consecutive cycles (Table 3). Most often $\mathrm{NaOH}, \mathrm{HCl}, \mathrm{HNO}_{3}$ and EDTA base solutions were employed for regeneration of PMNPs. ${ }^{\mathbf{1 , 3 , 1 3 , 6 0}}$ It is considered that regeneration solution should be non-toxic, clean, low cost and easy to make and handle. However, these aspects were rarely investigated. Furthermore, others aspects such as solution contact time, volume of regeneration solution vs. wastewater, regeneration solution selection and concentration need to be optimized. In case of reusability, adsorbent stability and consecutive recycling is important regarding economic concerns. Hence, PMNPs should be stable during treatment which can sustain chemical, physical and biological changing.

Numerous studies have shown regeneration and reusability of PMNPs using acidic medium ( $\mathrm{pH}$ range 2-3) because in most of the cases adsorptive removal of metal ions were lower at lower $\mathrm{pH}^{., 155,60}$

In few studies, basic medium of $\mathrm{NaOH}$ was also used for the regeneration as shown in Table 3. A slightly decrease in adsorption capacity (from 34.8 to $37.9 \mathrm{mg} \mathrm{g}^{-1}$ ) was noticed in case of nickel ion (Ni(II)) in consecutive five cycles, when PMNPs were regenerated using $\mathrm{HCl}$ solution at $\mathrm{pH}$ 2.19. Similarly, in case of others metallic ions a slight decrease in removal performance was noticed (Table 3). This decline in removal efficiency might be due to degradation of organic functional groups of plants metabolites during regeneration with acidic medium, loss of stability by the dissolution or leakage of iron that could change the morphology and magnetic behavior of PMNPs which eventually will create difficulty for separating 


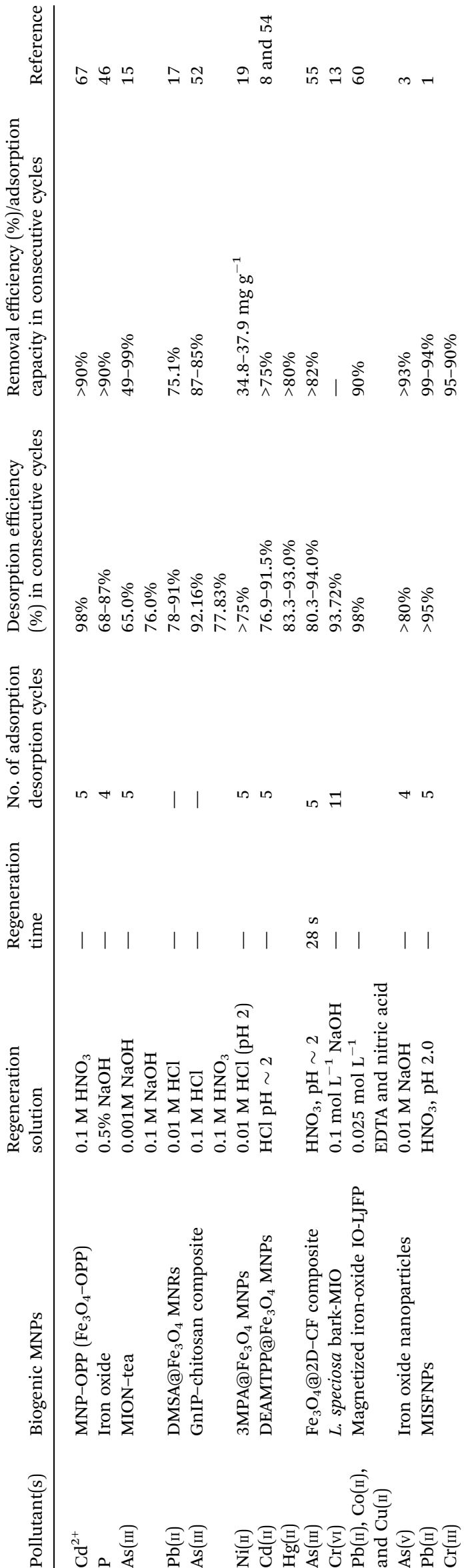

adsorbent from the system, ${ }^{8,54,55,60}$ and decreasing of available active sites on the surface of adsorbent. ${ }^{52,67}$ It is recommended that more research efforts are needed to address these aspects and to make phytogenic based WWT systems more efficient. Hence, in addition, phytogenic stability study is urgently needed to make treatment technology for commercial application. Because once the stability disturb, destruction of organic functional groups and dissolution or leakage of iron will occur due to the weak bindings that will cause loss of magnetic properties of the adsorbent, thereby creating separation of adsorbent from solution. Therefore, more research efforts are needed to handle these challenges.

\section{Future perspectives}

Due to clean, non-toxic, environmental friendly, easy fabrication and handling protocol of PMNPs using plant metabolites as reducing and capping agents, green nanotechnology has demonstrated as a next generation technology for WWT that can produce zero effluent discharge. However, some of the future perspectives are essential to be mention like;

- The long term exposure of these fabricated by-product regarding human health and sustainability is need to be investigated. Thus more research efforts are required to authorize these fabricated by-products from desorbed pollutants.

- Although fabrication protocol of PMNPs is simple and environmental friendly but some challenging aspects (solution extracts volume, temperature, solvent type, $\mathrm{pH}$, strength of precursor and functional groups from plant metabolites) should be optimized because these can change magnetic behavior and saturation magnetization value of the fabricated PMNPs.

- Moreover, pollutant removal and biomass separation may destroy PMNPs stability which eventually would increase treatment cost. Therefore, further research efforts are required to formulate PMNPs morphology and saturation magnetization value by optimizing fabrication procedure which eventually will improve pollutant removal performance and magnetic separability.

- Further researcher is needed to develop noble PMNPs with wide range of organic functional groups by manipulating plant metabolites and fabrication protocol, not only for selective removal but also for co-existing ions and multi type pollutants.

- To-date, there is no study available which can address costeffectiveness fabrication of PMNPs compare to physical and chemical methods. Therefore cost analysis is also desired in term of expenses and production.

- Moreover, for biomedical applications, biocompatibility studies are also needed.

\section{Conclusion}

Green nanotechnology is rapidly participating in the removal of emerging pollutants, textile dyes, metallic ions and organic pollutants from domestic and industrial wastewaters. The superior pollutants removal performance of PMNPs and non- 
toxic fabrication protocol are attracting researcher's attention in the following ways;

- Development of PMNPs is easy, safe and fast process than other biological routes particularly than microbes.

- Dynamic morphology, super paramagnetic nature, high saturation magnetization value makes PMNPs prominent for biomedical and environmental protection applications. However a controlled/optimized fabrication protocol is required to make PMNPs along-with desired morphology and organic functional groups that can employ for wide range of pollutants removal and metals recovery.

- PMNPs can easily be separated and reused because of their super paramagnetic behavior and high stability.

- Moreover, desorbed pollutants on PMNPs can be employed as resource recovery.

- Overall, green nanotechnology using plants is not only an environmental friendly option but also a promising technology for low economy countries that can also fulfill concept of zero effluent discharge after WWT using minimum cost and energy.

\section{Conflicts of interest}

The authors declare that there has no conflict of interest about this review manuscript.

\section{Author contributions}

All authors contributed to the analysis of data and preparation of the manuscript.

\section{Acknowledgements}

This work was supported by the State Key Laboratory of Environmental Criteria and Risk Assessment (No. SKLECRA 2013FP12) and Shandong Province Key Research and Development Program (2016GSF115040). The first author would also like to thank for the financial support by the Chinese Scholarship Council, China (CSC No: 2016GXYO20).

\section{Notes and references}

1 L. P. Lingamdinne, Y. Y. Chang, J. K. Yang, J. Singh, E. H. Choi, M. Shiratani and P. Attri, Chem. Eng. J., 2017, 307, 74-84.

2 C. Prasad, G. Yuvaraja and P. Venkateswarlu, J. Magn. Magn. Mater., 2017, 424, 376-381.

3 C. M. Martínez, G. M. López, J. L. Barriada, R. Herrero and M. E. S. Vicente, Chem. Eng. J., 2016, 301, 83-91.

4 I. Ali, C. Peng, Z. M. Khan and I. Naz, J. Basic Microbiol., 2017, 9999, 1-10.

5 C. Su, J. Hazard. Mater., 2017, 322, 48-84.

6 S. Saif, A. Tahir and Y. Chen, Nanomaterials, 2016, 6, 209.

7 K. S. Siddiqi, A. Rahman and A. Husen, Nanoscale Res. Lett., 2016, 11, 498.

8 S. Venkateswarlu and M. Yoon, RSC Adv., 2015a, 5, 6544465453.
9 D. Mukherjee, S. Ghosh, S. Majumdar and K. Annapurna, J. Environ. Chem. Eng., 2016, 4, 639-650.

10 C. Mystrioti, D. Sparis, N. Papasiopi, A. Xenidis, D. Dermatas and M. Chrysochoou, Bull. Environ. Contam. Toxicol., 2015, 94, 302-307.

11 P. Cheera, S. Karlapudi, G. Sellola and V. Ponneri, J. Mol. Liq., 2016, 221, 993-998.

12 C. P. Devatha, A. K. Thalla and S. Y. Katte, J. Cleaner Prod., 2016, 139, 1425-1435.

13 S. Srivastava, S. B. Agrawal and M. K. Mondal, J. Environ. Sci., 2017, 55, 283-293.

14 F. Buazar, N. M. H. Baghlani, M. Badri, M. Kashisaz, N. A. Khaledi and F. Kroushawi, Starch/Staerke, 2016, 68, 796-804.

15 S. Lunge, S. Singh and A. Sinha, J. Magn. Magn. Mater., 2014, 356, 21-31.

16 S. Machado, J. G. Pacheco, H. P. A. Nouws, J. T. Albergaria and M. C. Delerue, Sci. Total Environ., 2015, 533, 76-81.

17 S. Venkateswarlu, B. N. Kumar, B. Prathima, Y. SubbaRao and N. V. V. Jyothi, Arabian J. Chem., 2014, DOI: 10.1016/ j.arabjc.2014.09.006.

18 M. Fazlzadeh, K. Rahmani, A. Zarei, H. Abdoallahzadeh, F. Nasiri and R. Khosravi, Adv. Powder Technol., 2016, 28(1), 122-130.

19 S. Venkateswarlu, B. N. Kumar, B. Prathima, K. Anitha and N. V. V. Jyothi, Phys. B, 2015, 457, 30-35.

20 X. Qu, P. J. Alvarez and Q. Li, Water Res., 2013, 47, 3931-3946. 21 S. Srivastava, S. B. Agrawal and M. K. Mondal, Environ. Sci. Pollut. Res., 2015, 22, 15386-15415.

22 N. Pantidos and L. E. Horsfall, J. Nanomed. Nanotechnol., 2014, 5, 1.

23 V. K. Sharma, J. Filip, R. Zboril and R. S. Varma, Chem. Soc. Rev., 2015, 44, 8410-8423.

24 A. B. Seabra, P. Haddad and N. Duran, IET Nanobiotechnol., 2013, 7, 90-99.

25 D. Sharma, S. Kanchi and K. Bisetty, Arabian J. Chem., 2015, DOI: 10.1016/j.arabjc.2015.11.002.

26 M. Shah, D. Fawcett, S. Sharma, S. K. Tripathy and G. E. J. Poinern, Materials, 2015, 8, 7278-7308.

27 M. Herlekar, S. Barve and R. Kumar, J. Nanopart., 2014, 2014, 140614.

28 V. V. Makarov, A. J. Love, O. V. Sinitsyna, S. S. Makarova, I. V. Yaminsky, M. E. Taliansky and N. O. Kalinina, Acta Naturae., 2014, 6(1), 35-44.

29 S. Ahmed, M. Ahmad, B. L. Swami and S. Ikram, J. Adv. Res., 2016, 7, 17-28.

30 F. Cai, J. Li, J. Sun and Y. Ji, Chem. Eng. J., 2011, 175, 70-75.

31 H. P. Song, X. G. Li, J. S. Sun, S. M. Xu and X. Han, Chemosphere, 2008, 72, 616-621.

32 Y. Wang, H. Gao, J. Sun, J. Li, Y. Su, Y. Ji and C. Gong, Desalination, 2011, 270, 258-263.

33 S. Huiping, L. Xingang, L. C. Huaigang and C. Fangqin, Desalin. Water Treat., 2013, 51, 3864-3870.

34 X. Xiao, W. W. Zhu, H. Yuan, W. W. Li, Q. Li and H. Q. Yu, Biochem. Eng. J., 2016, 105, 214-219.

35 H. Zhou, H. Pan, J. Xu, W. Xu and L. Liu, J. Hazard. Mater., 2016, 304, 434-440. 
36 T. J. Baker, C. R. Tyler and T. S. Galloway, Environ. Pollut., 2014, 186, 257-271.

37 J. J. Jacob and K. Suthindhiran, Mater. Sci. Eng., C, 2016, 68, 919-928.

38 U. Shanker, V. Jassal, M. Rani and B. S. Kaith, Int. J. Environ. Anal. Chem., 2016, 96, 801-835.

39 T. Viswanathan, US Pat., 8,167,973, Board Of Trustees Of The University Of Arkansas, 2012.

40 T. Viswanathan, US Pat., 8,574,337, Board Of Trustees Of The University Of Arkansas, 2013.

41 T. Viswanathan, US Pat., 8,790,615, Board Of Trustees Of The University Of Arkansas, 2014.

42 T. Viswanathan, US Pat., 8,753,603, Board Of Trustees Of The University Of Arkansas, 2014.

43 T. Viswanathan, US Pat., 8,920,688, Board Of Trustees Of The University Of Arkansas, 2014.

44 T. Viswanathan, US Pat., 9,169,139, Board Of Trustees Of The University Of Arkansas, 2015.

45 T. Viswanathan, US Pat., 9,095,837, Broad of Trustees of the University of Arkansas, 2015.

46 S. K. Ramasahayam, G. Gunawan, C. Finlay and T. Viswanathan, Water, Air, Soil Pollut., 2012, 223, 48534863.

47 S. Venkateswarlu, Y. S. Rao, T. Balaji, B. Prathima and N. V. V. Jyothi, Mater. Lett., 2013, 100, 241-244.

48 S. Machado, S. L. Pinto, J. P. Grosso, H. P. A. Nouws, J. T. Albergaria and M. C. Delerue, Sci. Total Environ., 2013a, 445, 1-8.

49 S. Phumying, S. Labuayai, C. Thomas, V. Amornkitbamrung, E. Swatsitang and S. Maensiri, Appl. Phys. A, 2013, 111, 11871193.

50 R. Khandanlou, M. B. Ahmad, K. Shameli, E. Saki and K. Kalantari, Int. J. Mol. Sci., 2014, 15, 18466-18483.

51 S. Venkateswarlu, B. N. Kumar, C. H. Prasad, P. Venkateswarlu and N. V. V. Jyothi, Phys. B, 2014, 449, 67-71.

52 K. S. Prasad, P. Gandhi and K. Selvaraj, Appl. Surf. Sci., 2014, 317, 1052-1059.

53 H. Mihir and B. Siddhivinayak, Int. J. Adv. Res., 2015, 3, 331334.

54 S. Venkateswarlu and M. Yoon, Dalton Trans., 2015b, 44, 18427-18437.

55 S. Venkateswarlu, D. Lee and M. Yoon, ACS Appl. Mater. Interfaces, 2016, 8, 23876-23885.
56 A. Demir, R. Topkaya and A. Baykal, Polyhedron, 2013, 65, 282-287.

57 Y. Cai, Y. Shen, A. Xie, S. Li and X. Wang, J. Magn. Magn. Mater., 2010, 322, 2938-2943.

58 S. Machado, W. Stawiński, P. Slonina, A. R. Pinto, J. P. Grosso, H. P. A. Nouws, J. T. Albergaria and M. C. Delerue, Sci. Total Environ., 2013b, 461, 323-329.

59 M. Pattanayak and P. L. Nayak, World J. Nano. Sci. Technol., 2013, 2, 06-09.

60 L. P. Lingamdinne, J. K. Yang, Y. Y. Chang and J. R. Koduru, Hydrometallurgy, 2016, 165, 81-89.

61 G. E. Hoag, J. B. Collins, J. L. Holcomb, J. R. Hoag, M. N. Nadagouda and R. S. Varma, J. Mater. Chem., 2009, 19, 8671-8677.

62 M. N. Nadagouda, A. B. Castle, R. C. Murdock, S. M. Hussain and R. S. Varma, Green Chem., 2010, 12, 114-122.

63 T. Shahwan, S. A. Sirriah, M. Nairat, E. Boyacı, A. E. Eroğlu, T. B. Scott and K. R. Hallam, Chem. Eng. J., 2011, 172, 258266.

64 P. Panneerselvam, N. Morad and K. A. Tan, J. Hazard. Mater., 2011, 186, 160-168.

65 V. Smuleac, R. Varma, S. Sikdar and D. Bhattacharyya, J. Membr. Sci., 2011, 379, 131-137.

66 K. A. Tan, N. Morad, T. T. Teng, I. Norli and P. Panneerselvam, APCBEE Proc., 2012, 1, 83-89.

67 V. K. Gupta and A. Nayak, Chem. Eng. J., 2012, 180, 81-90.

68 M. Senthil and C. Ramesh, Dig. J. Nanomater. Bios., 2012, $7(3), 1655-1660$.

69 K. M. Kumar, B. K. Mandal, K. S. Kumar, P. S. Reddy and B. Sreedhar, Spectrochim. Acta, Part A, 2013, 102, 128-133.

70 X. Weng, L. Huang, Z. Chen, M. Megharaj and R. Naidu, Ind. Crops Prod., 2013, 51, 342-347.

71 M. Pattanayak and P. L. Nayak, Int. J. Plant, Anim. Environ. Sci., 2013, 3, 68-78.

72 M. Mahdavi, F. Namvar, M. B. Ahmad and R. Mohamad, Molecules, 2013, 18, 5954-5964.

73 T. Wang, J. Lin, Z. Chen, M. Megharaj and R. Naidu, J. Cleaner Prod., 2014, 83, 413-419.

74 L. Huang, X. Weng, Z. Chen, M. Megharaj and R. Naidu, Spectrochim. Acta, Part A, 2014, 117, 801-804.

75 K. A. Tan, N. Morad, T. T. Teng and I. Norli, J. Taiwan Inst. Chem. Eng., 2015, 54, 96-108.

76 S. Venkateswarlu, S. H. Kumar and N. V. V. Jyothi, Water Resour. Ind., 2015, 12, 1-7. 